\title{
Monitoring the construction of a large-diameter caisson in sand
}

\section{Ronan Royston BE, DPhil}

Design Engineer, Ward and Burke Construction Ltd, Bourne End, UK; Department of Engineering Science, University of Oxford, Oxford, UK

Brian B. Sheil BE, PhD

Royal Academy of Engineering Research Fellow, Department of

Engineering Science, University of Oxford, Oxford, UK

(corresponding author: brian.sheil@eng.ox.ac.uk)
Byron W. Byrne BE (Hons), BCom, MA, DPhil

Ørsted/Royal Academy of Engineering Research Chair in Advanced Geotechnical Design, Professor of Engineering Science, Department of Engineering Science, University of Oxford, Oxford, UK

Large-diameter open caissons are a widely used construction solution for deep foundations, underground storage and attenuation tanks, pumping stations, and launch and reception shafts for tunnel boring machines. The sinking phase presents a number of challenges during construction, including maintaining caisson verticality, controlling the rate of sinking and minimising soil resistance through the use of lubricating fluids. This paper describes the instrumentation and monitoring of a large-diameter caisson on a UK construction site. The caisson was instrumented for the measurement of settlement and tilt, soil-structure interaction contact stresses and structural performance. A key objective for the monitoring project was to provide real-time feedback to the site engineering team to inform the construction process. The monitored data revealed the occurrence of complex soil-structure interactions during sinking that are not readily captured by existing prescriptive design approaches. This case history provides valuable information for the development of an improved basis for design as well as an important frame of reference for future monitoring projects.

\section{Notation}

$\boldsymbol{B} \quad$ buoyant uplift force

$C_{\mathrm{b}} \quad$ strain gauge calibration factor

$C_{\mathrm{k}} \quad$ logger calibration factor

$\boldsymbol{F} \quad$ vertical frictional resistance of the soil

$f \quad$ vibrating wire (VW) frequency measurement

$I_{\mathrm{D}} \quad$ relative density of soil

$K \quad$ coefficient of lateral earth pressure

$N_{\text {kt }} \quad$ cone penetration test (CPT) cone factor

$p_{\text {ref }} \quad$ reference pressure

$p \quad$ fluid pressure acting on exterior of caisson walls

$q_{\mathrm{s}} \quad$ cone sleeve friction

$q_{\mathrm{t}} \quad$ cone tip resistance

$R_{\mathrm{f}} \quad$ CPT friction ratio

$S \quad$ sinking coefficient

$s_{\mathrm{u}} \quad$ undrained shear strength of soil

$t_{\mathrm{w}} \quad$ caisson wall thickness

$u$ pore pressure

$V \quad$ vertical bearing resistance of soil

$\boldsymbol{W}$ self-weight of caisson walls

$z \quad$ depth below ground level

$\alpha_{\mathrm{c}} \quad$ coefficient of thermal expansion of concrete

$\alpha_{\mathrm{g}} \quad$ coefficient of thermal expansion of VW strain gauge

$\beta \quad$ inclination of caisson cutting face

$\gamma^{\prime} \quad$ effective unit weight of soil

$\Delta T \quad$ temperature difference

$\delta \quad$ caisson-soil interface friction angle

$\sigma_{\mathrm{n}} \quad$ total normal stress acting on exterior of caisson walls

$\sigma_{\mathrm{v} 0} \quad$ total vertical in situ stress

$\sigma_{\mathrm{v} 0}^{\prime} \quad$ effective vertical in situ stress

$\tau \quad$ shear stress exerted by soil on exterior of caisson walls $\phi^{\prime}$

\section{Introduction}

Growth in urban populations has prompted considerable efforts to exploit underground space for the expansion of critical infrastructure. In particular, deep large-diameter caissons/ shafts are increasingly employed for underground developments. The geotechnical and structural performance of caissons is a critical design concern to ensure safe and efficient construction while also preventing damage to existing nearby infrastructure. Given high-profile construction projects planned worldwide, there is significant motivation to optimise caisson construction operations.

In the reported literature, there appears to be a lack of highquality case histories exploring caisson performance - perhaps unsurprising given the difficulty and expense of instrumenting live construction sites. New and Bowers (1994) reported the monitoring of ground movements during shaft construction for the Heathrow Express trial tunnel. The monitored data were subsequently used to inform the development of simplified prescriptive design methods. Ho (2002) explored innovative approaches for the construction of large-diameter caissons in boulder clay. Chandler et al. (1984) and Safiullah (2005) presented case studies of caissons used for bridge piers in Bangladesh, many of which were over $100 \mathrm{~m}$ deep. Significant ground subsidence during construction became apparent, due to upward heave of the soil inside the caisson, subsequently inducing damage to nearby infrastructure. Allenby et al. (2009) describe the process of sinking dry and wet open caissons through four construction case histories, highlighting the importance of control measures to satisfy verticality and structural integrity during construction. Abdrabbo and Gaaver (2012) documented a case history of a $20 \mathrm{~m}$ dia. caisson that wedged 
during sinking due to the development of excessive soilstructure frictional stresses. More recently, Schwamb (2014) and Schwamb et al. $(2014,2016)$ documented the settlement and performance monitoring during the construction of a deep shaft using diaphragm walls.

This paper adds to the existing literature by describing the development of a caisson monitoring system and its deployment on a live construction site in Blackpool, UK. A key objective of the monitoring project was to provide real-time feedback to the site engineering team, to inform and aid the construction process. The caisson was instrumented for the measurement of sinking movements and tilt, soil-structure interaction contact stresses and wall strains throughout the construction process. The monitored data revealed that the soil-structure interaction contact stresses exhibited considerable fluctuations during sinking and were also dependent on the elevation of the monitoring point relative to the caisson cutting face. These complex soil-structure interactions during sinking are not readily captured by existing prescriptive design approaches. This work also motivates the development of new design methods.

\section{Reinforced concrete caisson design}

Reinforced concrete caisson construction involves a complex system of concurrent casting of the concrete walls and excavation of the soil within and beneath the caisson. This process encourages the caisson to sink into the ground. Caisson sinking therefore involves subtle balancing between the resistance generated from soil-structure interaction and the self-weight of the caisson walls. An accurate estimate of the various soil-structure interactions is crucial to maintain controlled sinking: over-prediction leads to excessive and dangerous movements of the caisson while under-prediction could result in the caisson becoming wedged.

Figure 1 illustrates a typical section through a caisson wall. An angled 'cutting face' at the base of the caisson aids the sinking

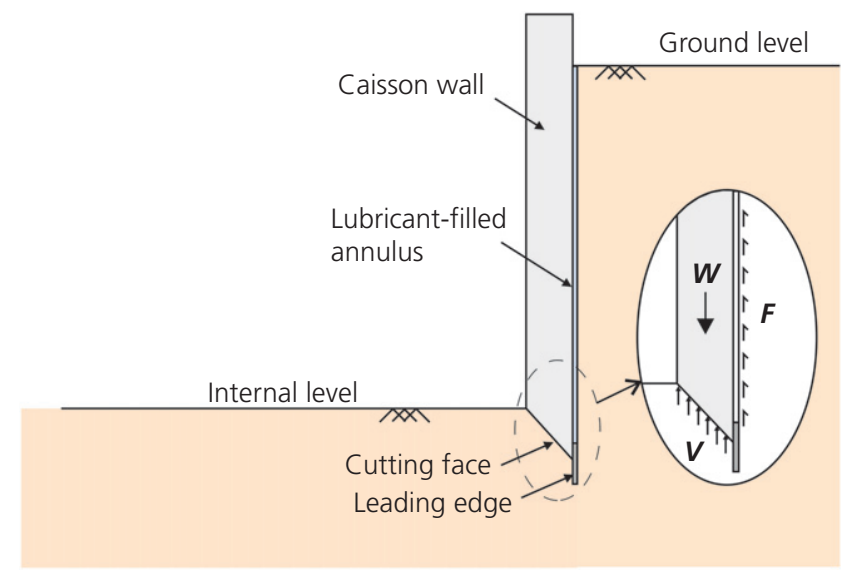

Figure 1. Schematic of cross-section through caisson wall showing typical features and definition of forces process and ensures soil failure is mobilised towards the inside of the caisson for excavation. An annulus that encircles the caisson is constructed using a leading steel 'cutting edge' located at the base of the wall (Newman and Wong, 2011). This annulus is typically pumped with lubricant to minimise the development of soil-structure frictional stresses. Current practice involves the use of excessively thick caisson wall sections to provide sufficient self-weight $(W)$ to overcome the soil bearing resistance $(V)$ beneath the walls as well as the soil frictional resistance $(F)$ acting on the exterior face of the caisson (see Figure 1). A rudimentary sinking coefficient $(S)$ can be defined as the ratio of the total downward force to the total upward soil resistance (Yao et al., 2014)

$$
\text { 1. } S=\frac{W-B}{V+F}
$$

where $B$ is the buoyant uplift force, if applicable.

Nonveiller (1987) recommends a value of $S \geq 2$ to achieve controlled sinking. In practice, $V$ and $F$ are difficult to predict as there is very little guidance available in the public domain. In particular, $V$ is highly dependent on the adopted angle of the cutting face $(\beta)$. For this reason, $\beta=45^{\circ}$ is typically adopted in design, irrespective of the site conditions (Fischer et al., 2004; Royston et al., 2016). Several case studies have reported the successful use of an over-cut to reduce $F$ in cohesive soils. Nonveiller (1987) reports the use of a $200 \mathrm{~mm}$ over-cut for a $27 \mathrm{~m}$ internal diameter caisson to allow for swelling of the surrounding clay. Fischer et al. (2004) report the use of a $150 \mathrm{~mm}$ over-cut for the successful construction of a $18 \mathrm{~m}$ internal diameter caisson. By contrast, a number of investigators have cautioned against relying on an over-cut to minimise $F$ in cohesionless materials (e.g. Stubbs, 1996; Tomlinson, 2001). Lack of research into this problem means significant uncertainty surrounds the determination of both $V$ and $F$, particularly in cohesionless soils.

\section{Anchorsholme Park construction project}

\subsection{Project overview}

The construction works at Anchorsholme Park were devised to improve bathing water quality along the seafront in Blackpool, UK, and mitigate the risk of flooding after periods of heavy rainfall. One component of the scheme entailed the construction of a $32 \mathrm{~m}$ internal diameter caisson for a new underground screening plant (Figure 2). Construction of the caisson began in February 2017 and was completed in July 2017 by Ward and Burke Construction Ltd. Once the screening plant is commissioned, the treated water will be pumped into the Irish Sea by way of a $5 \mathrm{~km}$ outfall.

\subsection{Site investigation}

The site investigation for the project included four boreholes and ten cone penetrations tests (CPTs) undertaken around the 
Monitoring the construction of

a large-diameter caisson in sand

Royston, Sheil and Byrne

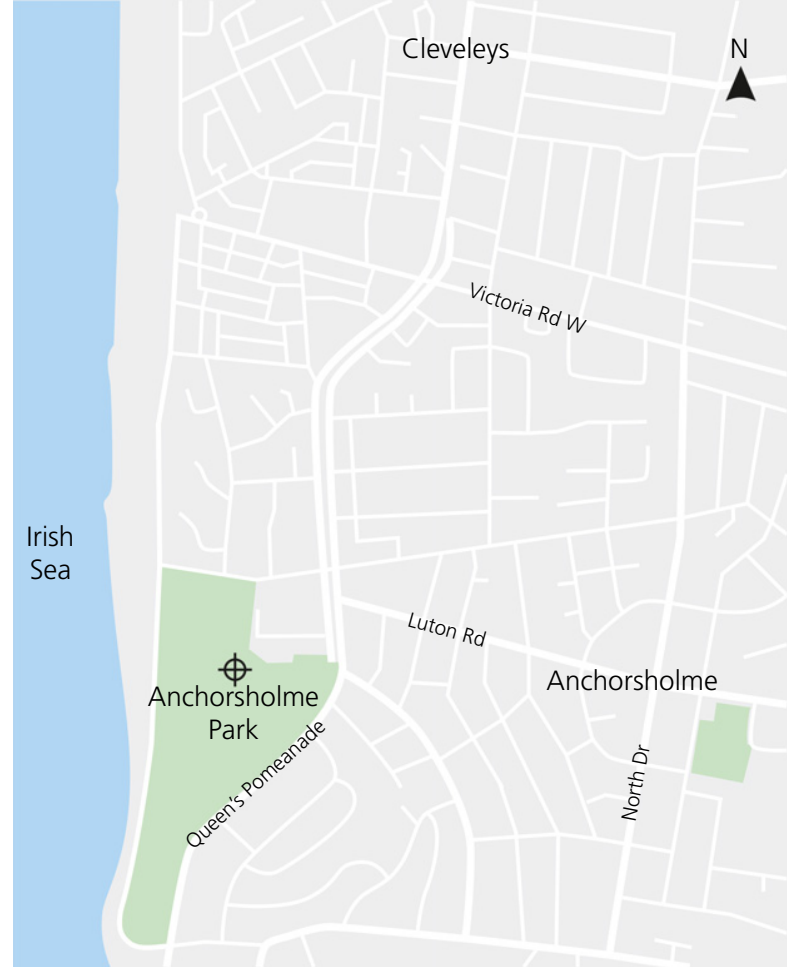

(a)

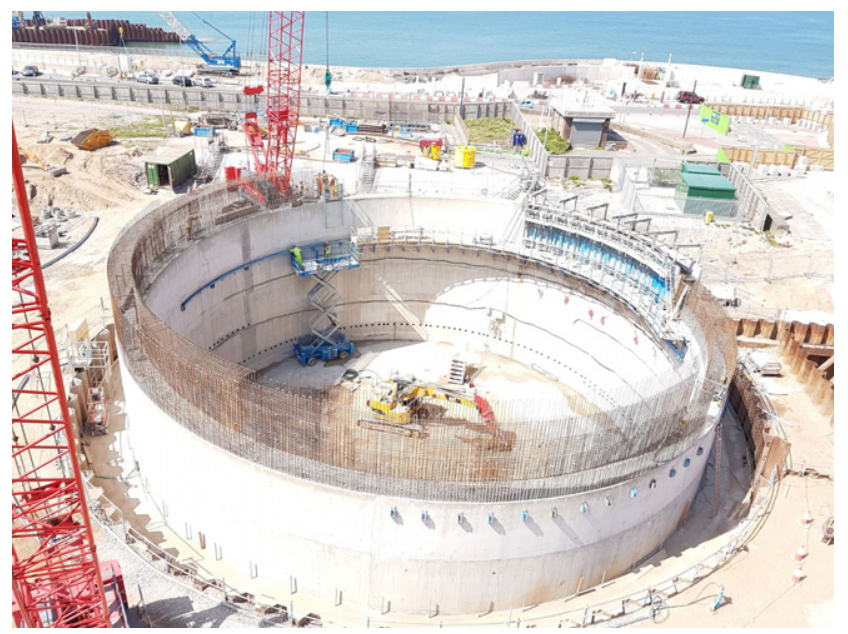

(b)

Figure 2. (a) Project location at Anchorsholme Park, Blackpool, UK; (b) caisson under construction

perimeter of the caisson, as shown in Figure 3(a). The stratigraphy inferred from the boreholes revealed dense sand with an intermediate soft clay layer in the upper section, overlying firmer clay. This is shown in Figure 3(b) where ground level corresponds to $5.8 \mathrm{~m}$ above Ordnance Datum (AOD). The lower clay stratum was encountered at a slightly greater depth towards the north-east of the caisson. Particle size distribution tests carried out at multiple levels revealed a uniform sand layer. Due to the close proximity of the site to the Irish Sea, piezometer measurements were observed to vary between $0 \mathrm{~m}$ AOD and $5 \mathrm{~m}$ AOD. Each CPT was penetrated to a depth of $-14 \mathrm{~m}$ AOD, slightly below the expected caisson depth, using a $36 \mathrm{~mm}$ dia. piezocone with a cone angle of $60^{\circ}$. Figure 4 shows the results of the CPTs (cone tip resistance $q_{\mathrm{t}}$, cone sleeve friction $q_{\mathrm{s}}$, friction ratio $R_{\mathrm{f}}$ and pore pressure $u$ ) and the inferred soil parameters (friction angle $\phi^{\prime}$, undrained shear strength $s_{\mathrm{u}}$ and relative density $I_{\mathrm{D}}$ ). Individual tests are indicated by the grey curves and the means of all ten tests are shown by the black curves. The angle of friction was backcalculated from the cone resistance following the work of Kulhawy and Mayne (1990)

2. $\phi^{\prime}=17.6+11 \ln Q_{\mathrm{t}}$

3. $Q_{\mathrm{t}}=\frac{q_{\mathrm{t}}-\sigma_{\mathrm{v} 0}}{\sigma_{\mathrm{v} 0}^{\prime}}$

where $\sigma_{\mathrm{v} 0}$ and $\sigma_{\mathrm{v} 0}^{\prime}$ are the total and effective vertical in situ stresses, respectively. Similarly, $I_{\mathrm{D}}$ was determined from $q_{\mathrm{s}}$ (again following Kulhawy and Mayne (1990))

4. $\quad I_{\mathrm{D}}=0.35 \ln \left(\frac{q_{\mathrm{c}}}{20}\right)$

5. $\quad q_{\mathrm{c}}=\frac{q_{\mathrm{s}} / p_{\mathrm{ref}}}{\sqrt{\sigma_{\mathrm{v} 0}^{\prime} / p_{\mathrm{ref}}}}$

where $p_{\text {ref }}$ is a reference pressure taken as $100 \mathrm{kPa}$ (Jamiolkowski et al., 2003). Finally, $s_{\mathrm{u}}$ was determined using the standard relationship

6. $s_{\mathrm{u}}=\frac{q_{\mathrm{t}}-\sigma_{\mathrm{v} 0}}{N_{\mathrm{kt}}}$

where $N_{\mathrm{kt}}$ is the cone factor. A value of $N_{\mathrm{kt}}=14$ was determined through calibration of the CPT results with triaxial tests undertaken on borehole samples of the deeper clay layer. Figure 4 indicates that the caisson was sunk predominantly through dense sand with $\phi^{\prime} \approx 40^{\circ}$ and $I_{\mathrm{D}} \approx 70 \%$. At caisson formation (around $-14 \mathrm{~m}$ AOD) there was stiff clay with $s_{\mathrm{u}}$ ranging between $400 \mathrm{kPa}$ and $500 \mathrm{kPa}$. A unit weight of $20 \mathrm{kN} / \mathrm{m}^{3}$ was assumed for both the sand and clay.

\subsection{Caisson construction details}

To ensure effective dewatering of the excavation during construction, sheet piles were first driven to a depth of $-16 \mathrm{~m}$ 
Geotechnical Engineering

Volume 175 Issue 3
Monitoring the construction of

a large-diameter caisson in sand

Royston, Sheil and Byrne

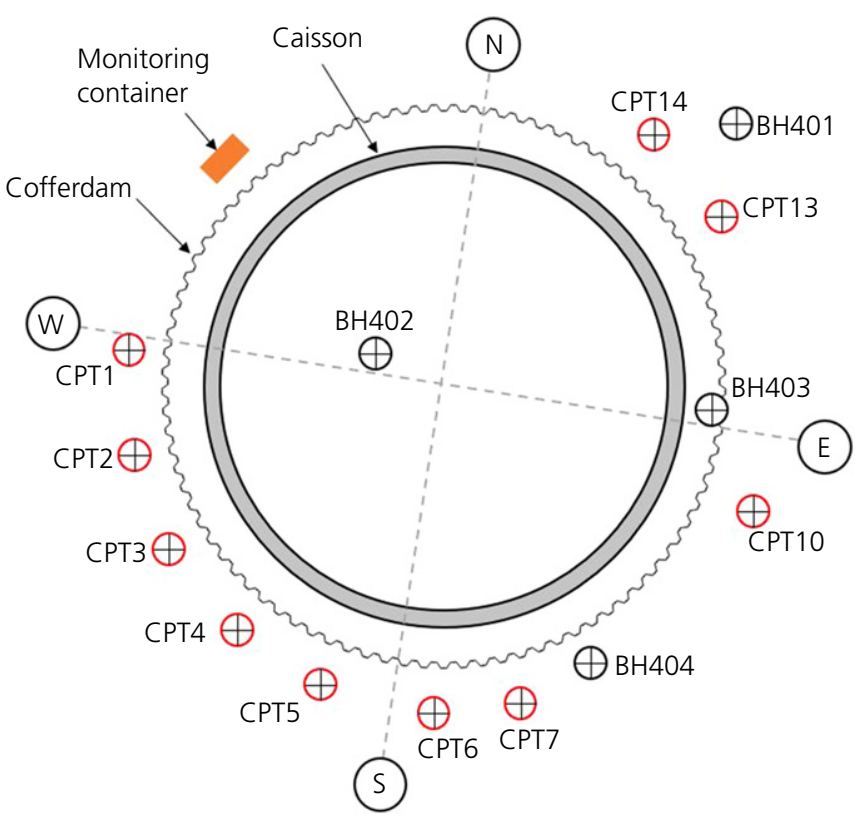

(a)

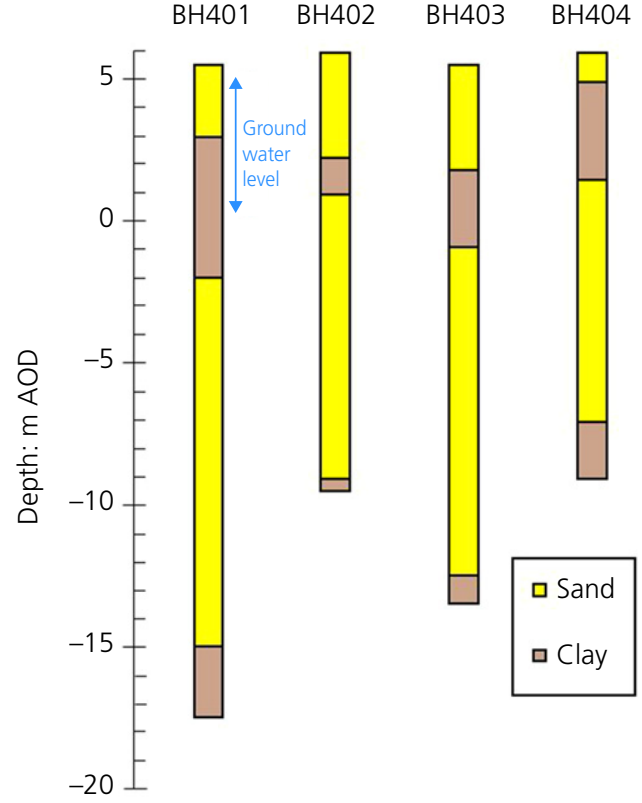

(b)

Figure 3. (a) Plan view of site layout showing locations of boreholes (BH401-BH404) and CPTs; (b) site stratigraphy determined from boreholes
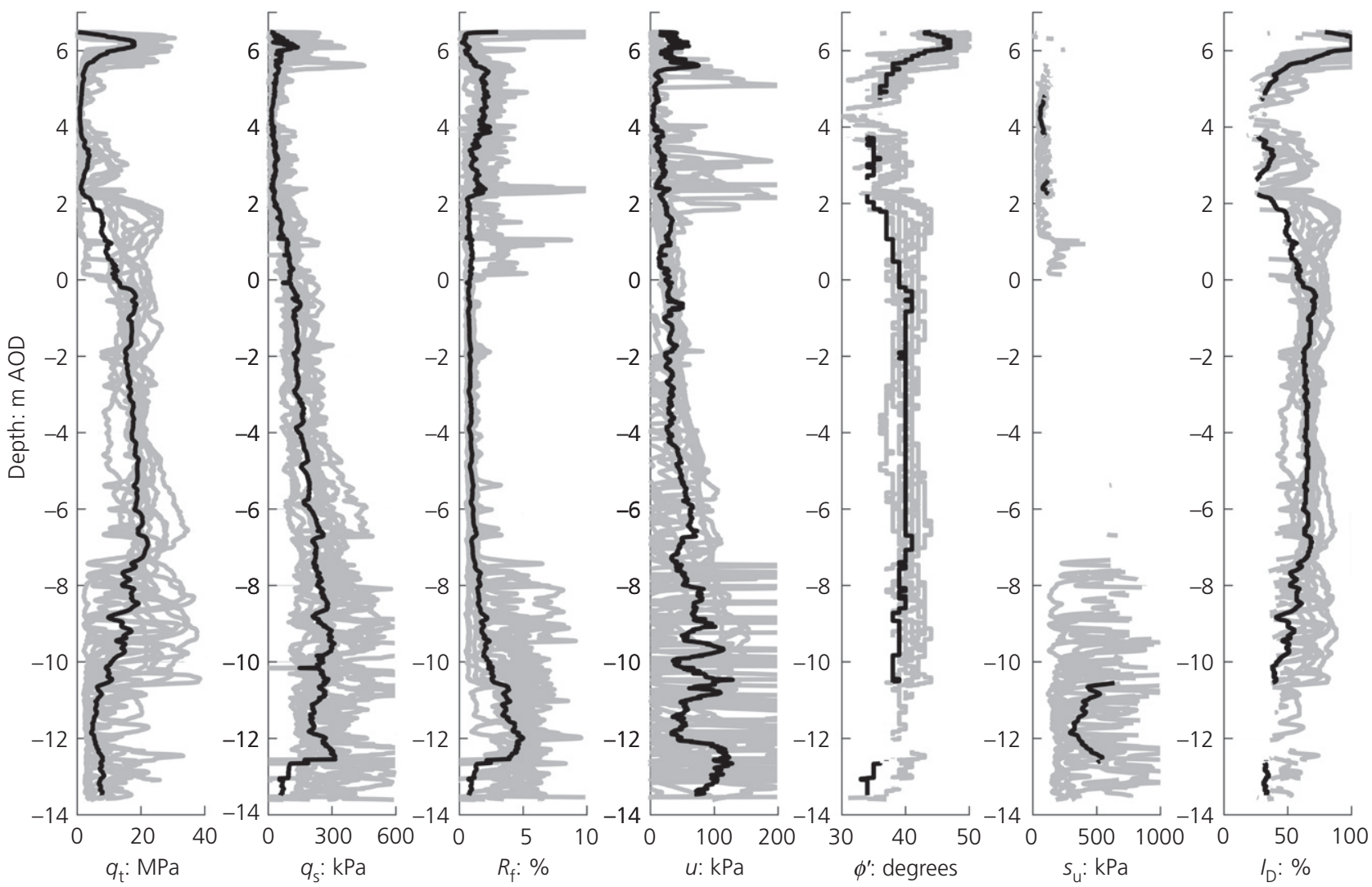

Figure 4. Results of CPTs undertaken around caisson at Anchorsholme Park (see locations in Figure 3(a)). The grey curves indicate individual CPTs and the black curves denote the mean of all ten CPTs 
AOD (founded in the lower clay layer). The sheet pile cofferdam was subsequently excavated to $-3.5 \mathrm{~m}$ AOD, supported internally by reinforced concrete ring beams at two elevations ( $2.5 \mathrm{~m}$ AOD and $1.6 \mathrm{~m}$ AOD). Caisson wall construction began from the internal excavation level ( $-3.5 \mathrm{~m}$ AOD). The caisson had a wall thickness of $1.25 \mathrm{~m}$, a cutting face angle of $\beta=45^{\circ}$ and an over-cut of $75 \mathrm{~mm}$. To construct the caisson, a helical shuttering system was used to form the concrete. The helical shutter was set at a slope of $2^{\circ}$ and required eight pours of $55 \mathrm{~m}^{3}$ each to complete a $3 \mathrm{~m}$ high revolution of the caisson. The lubrication used in the annulus was a mix of Hydraul-Ez bentonite $\left(75 \mathrm{~kg} / \mathrm{m}^{3}\right)$, MX polymer $\left(10 \mathrm{~kg} / \mathrm{m}^{3}\right)$ and water, batched in a high-frequency mixer. Once the caisson reached formation level, a $1.5 \mathrm{~m}$ thick reinforced concrete base was constructed.

\section{Development of the real-time caisson monitoring system}

\subsection{Overview}

A central objective of this research was to provide the site team with real-time feedback to inform the caisson construction process. The instrumentation adopted to achieve this objective is listed in Table 1 and the sensor locations on the caisson wall are shown in Figure 5. All sensors apart from the vibrating wire (VW) strain gauges were logged using a National Instruments CompactDAQ system at a frequency of $1 \mathrm{~Hz}$; the VW strain gauges were logged using a separate Soil Instruments logger at a rate of $1 / 300 \mathrm{~Hz}$ (limited by the logger). Where possible, cables were cast through the centre of the reinforced concrete caisson walls for mechanical protection. Voltage drops due to long-distance transmission were compensated for using the 'remote sensing' function. In this mode, the CompactDAQ senses the actual bridge voltage at each sensor location and eliminates the gain errors caused by the wire resistances. Video monitoring was undertaken using a time-lapse camera placed $5 \mathrm{~m}$ above ground level, which was accessible to the project team during construction. All the data were processed in real time using LabView 2017 and presented to the site team for immediate action by means of portable tablets. The information provided included caisson tilt, sinking rate and soil-structure contact stresses. A remote router and wireless network repeaters ensured continuous connectivity around the site and within the caisson.

\subsection{Caisson elevation and tilt}

A bespoke liquid-level detection system was deployed on the caisson to monitor the elevation and tilt of the caisson during sinking (see Figure 6). The system comprised four pressure transducers (PTs) cast into the quarter points of the caisson wall. All four PTs (denoted $\mathrm{PT}_{1}-\mathrm{PT}_{4}$ ) were hydraulically linked by $0.5^{\prime \prime}(1.27 \mathrm{~cm})$ wire reinforced hosing to a header tank filled with de-aired water, as shown in Figure 7. The difference in pressure between the PTs and a reference PT $\left(\mathrm{PT}_{\text {ref }}\right)$ fixed at ground level enabled the level of the caisson at each location (relative to $\mathrm{PT}_{\text {ref }}$ ) to be deduced. The PTs were fitted within IP68 containers with a bleed valve to allow the

Table 1. Instrumentation installed on caisson

\begin{tabular}{llll}
\hline Measurement & Sensor type & Quantity & Notation $^{\text {a }}$ \\
\hline Liquid level detection system & Pressure transducer & 5 & $\mathrm{PT}_{x}$ \\
Soil-structure contact stresses & Three-axis load cell & 7 & $\mathrm{LC}_{x y}$ \\
Annulus lubricant pressure & Pressure transducer & 5 & $\mathrm{OPT}_{x y}$ \\
Wall hoop strain & Embedment-type vibrating wire strain gauge & 8 & WW $_{x}$
\end{tabular}

${ }^{a}$ The subscript $x$ denotes the sensor number in all instances, whereas the subscript $y$ denotes the corresponding instrumentation line (if applicable)

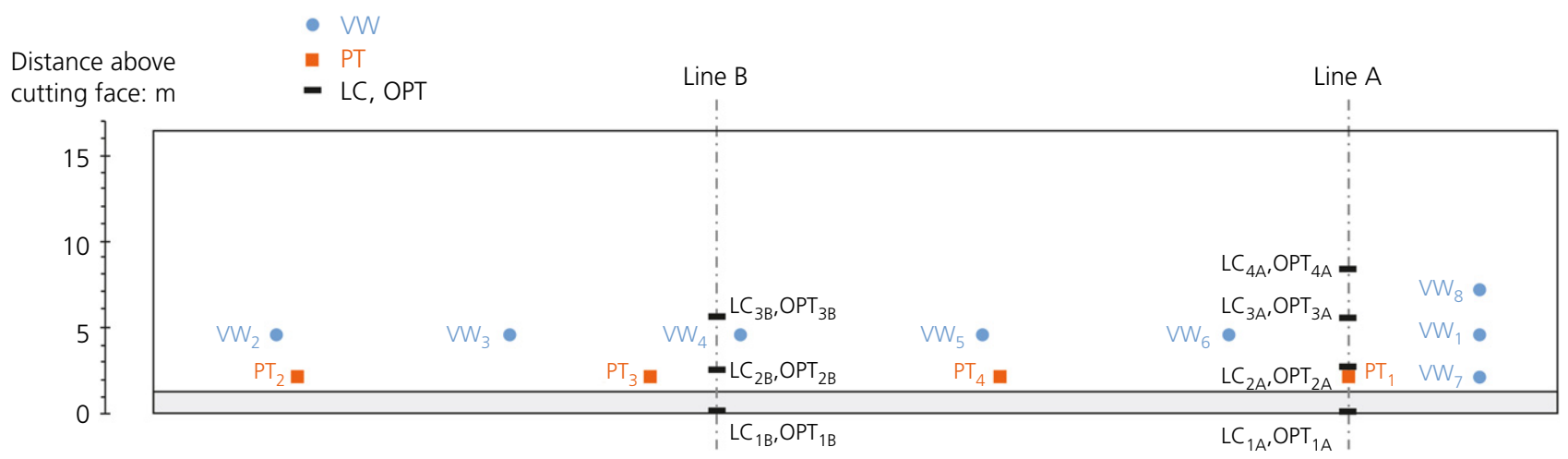

Figure 5. Rolled-out elevation of Anchorsholme Park shaft showing sensor locations. Note the concentration of sensors along two main lines at opposite sides of the shaft denoted line A and line B 


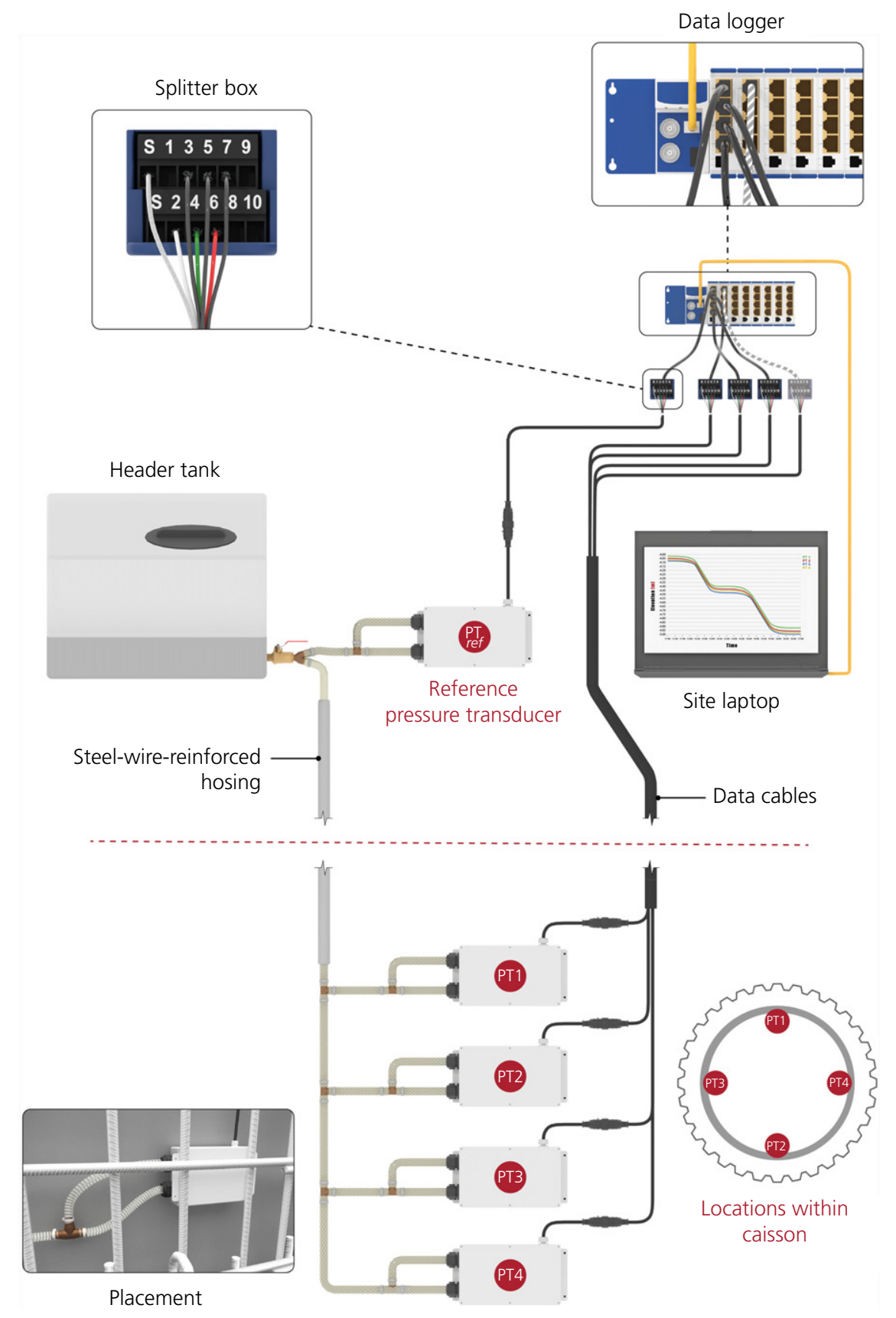

Figure 6. Schematic diagram of the layout of the level detection system comprising the header tank connected to $\mathrm{PT}_{\text {ref }}$ (fixed at ground level) and $\mathrm{PT}_{1}-\mathrm{PT}_{4}$ (fixed to caisson wall) by way of reinforced hose

system to be flushed during commissioning. The water was de-aired by applying a negative pressure to the header tank over a period of $24 \mathrm{~h}$. Due to the possibility of low on-site temperatures, one part anti-freeze was added to three parts water to reduce the freezing temperature to approximately $-10^{\circ} \mathrm{C}$. Green dye was also added to the mixture to aid the identification of air in the water lines. The density of the resulting solution was $10.14 \mathrm{kN} / \mathrm{m}^{3}$, determined by measurement on site.

\subsection{Soil-structure contact stresses}

Seven commercial three-axis load cells (LCs) supplied by Interface Force Measurements Ltd were used to monitor the normal force and shear force applied by the soil to a $100 \times$ $100 \mathrm{~mm}$ bearing plate on the exterior surface of the caisson (see Figure 8). The LCs were aligned to measure shear stresses acting vertically and circumferentially on the caisson wall, although the circumferential shear forces were not logged for 


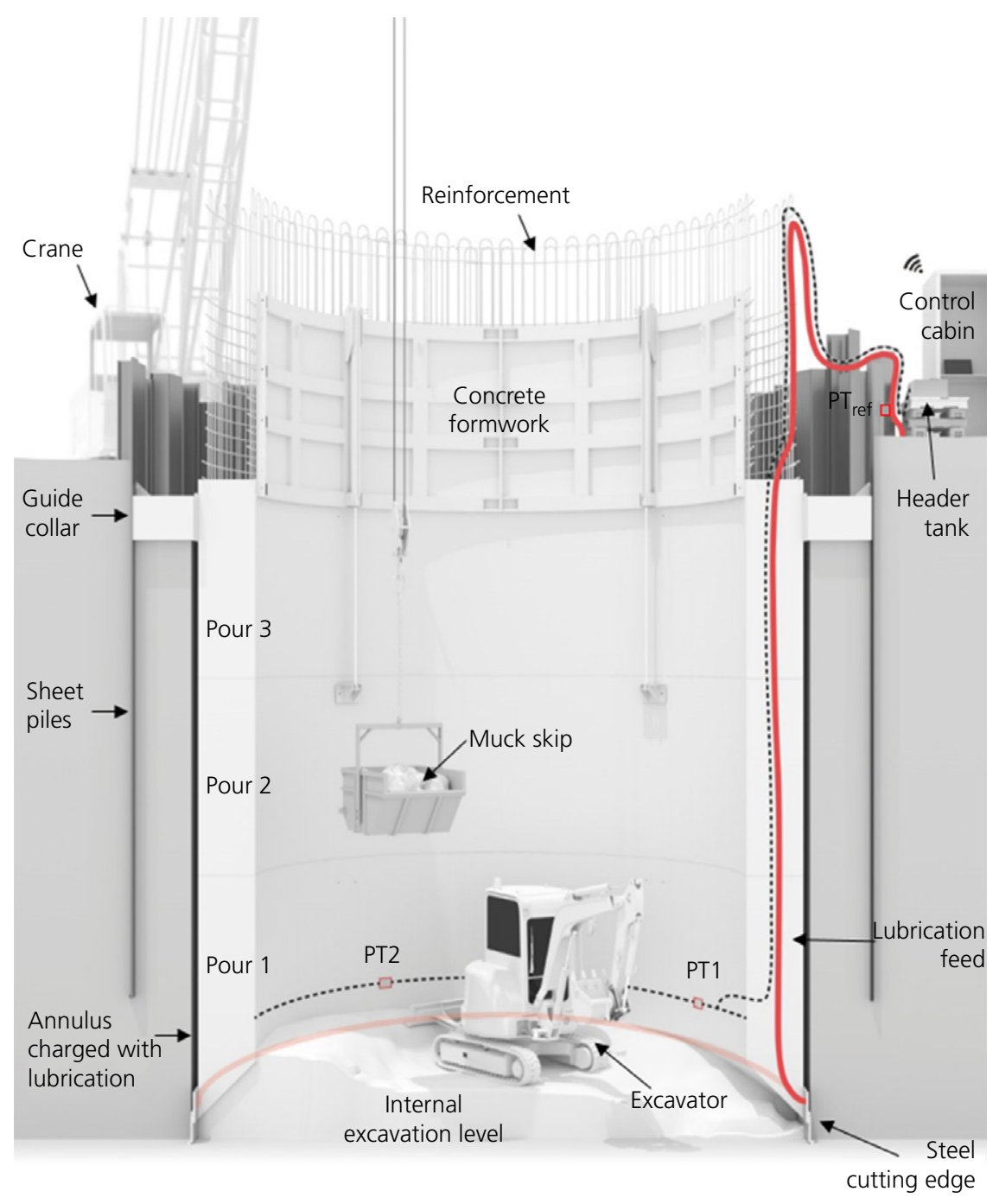

Figure 7. Schematic diagram showing typical layout of the bespoke liquid-level detection system developed for this project

this project. A series of bending beam elements inside the cells allowed measurement of up to $5 \mathrm{kN}$ in each direction. The LCs were located flush with the exterior face of the caisson using individual waterproof aluminium housings that could be cast directly into the wall. Each cell lid was isolated from the housing by a $1 \mathrm{~mm}$ gap filled with soft silicone rubber.

Two main 'lines' of instrumentation, line A and line B, were installed and aligned vertically on the caisson wall, as shown in Figure 5. There were four monitoring points on line $\mathrm{A}$ and three on line $\mathrm{B}$. The lower $\mathrm{LCs}$ on each line $\left(\mathrm{LC}_{1 \mathrm{~A}}\right.$ and $\left.\mathrm{LC}_{1 \mathrm{~B}}\right)$ were located in the leading cutting edge to measure contact stress in the virgin ground. The upper $\mathrm{LCs}\left(\mathrm{LC}_{2 \mathrm{~A}}-\mathrm{LC}_{4 \mathrm{~A}}, \mathrm{LC}_{2 \mathrm{~B}}\right.$ and $\mathrm{LC}_{3 \mathrm{~B}}$ ) were cast flush with the caisson wall to monitor conditions in the annulus; a PT was placed beside each of these LCs to monitor the lubricant pressure in the annulus $\left(\mathrm{OPT}_{2 \mathrm{~A}}-\mathrm{OPT}_{4 \mathrm{~A}}, \mathrm{OPT}_{2 \mathrm{~B}}\right.$ and $\left.\mathrm{OPT}_{3 \mathrm{~B}}\right)$.

\subsection{Caisson wall strains}

Eight embedment-type VW strain gauges were cast into the caisson wall to monitor the development of hoop strains during sinking. Six strain gauges $\left(\mathrm{VW}_{1}-\mathrm{VW}_{6}\right)$ were distributed around the circumference of the caisson, $5 \mathrm{~m}$ above the leading edge (see Figure 5). An additional strain gauge was placed $2.5 \mathrm{~m}$ and $7.5 \mathrm{~m}$ above the leading edge $\left(\mathrm{VW}_{7}\right.$ and $\mathrm{VW}_{8}$, respectively) to capture the vertical distribution of hoop strain. The VW strain gauges were tied to the steel reinforcement, $60 \mathrm{~mm}$ from the outside face of the caisson. Measurements of frequency $(f)$ recorded by the logger were converted into microstrain $(\mu \varepsilon)$ using calibration factors provided by the manufacturer as follows

7. $\mu \varepsilon=\left(C_{\mathrm{k}}(f) \times 10^{-4}\right) C_{\mathrm{b}}$ 
Monitoring the construction of

a large-diameter caisson in sand

Royston, Sheil and Byrne

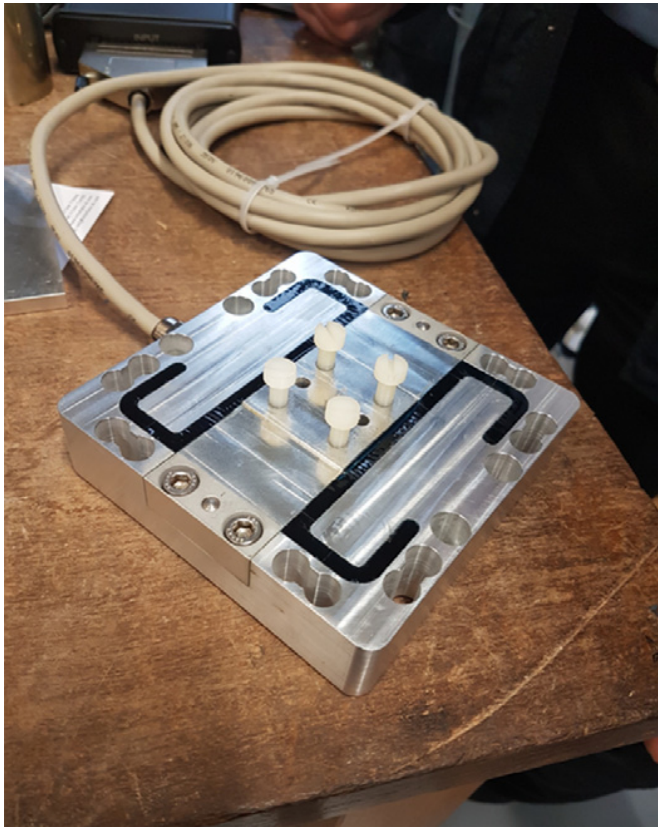

(a)

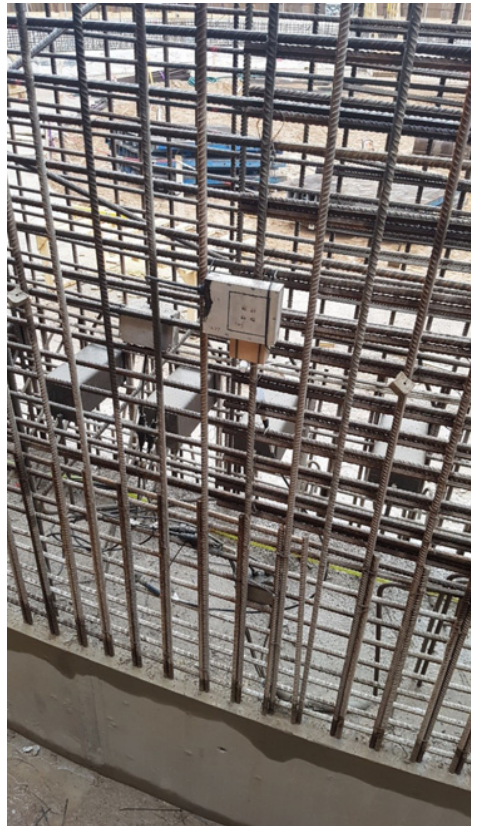

(b)

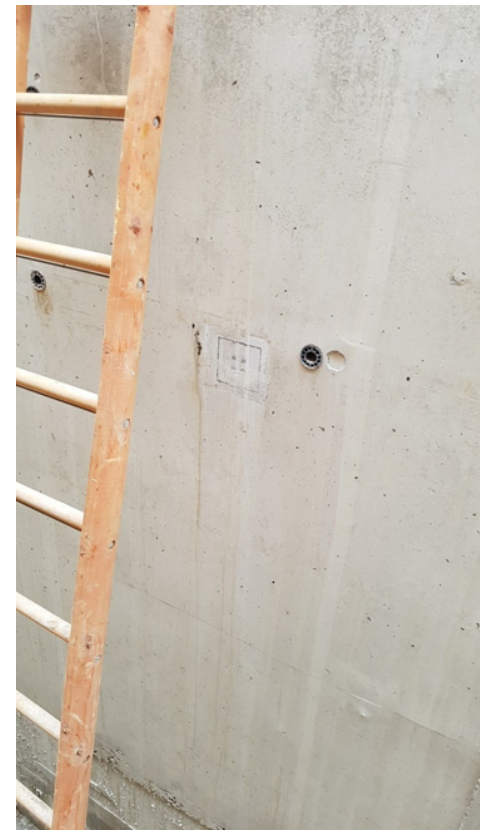

(c)

Figure 8. Three-axis LCs used for monitoring soil-structure normal and shear contact stresses: (a) sensor as procured; (b) sensor fitted within bespoke waterproofed aluminium housing and fixed to steel rebar prior to casting of the concrete walls; (c) sensor post-casting showing exposed $100 \mathrm{~mm}$ square 'sensing face'

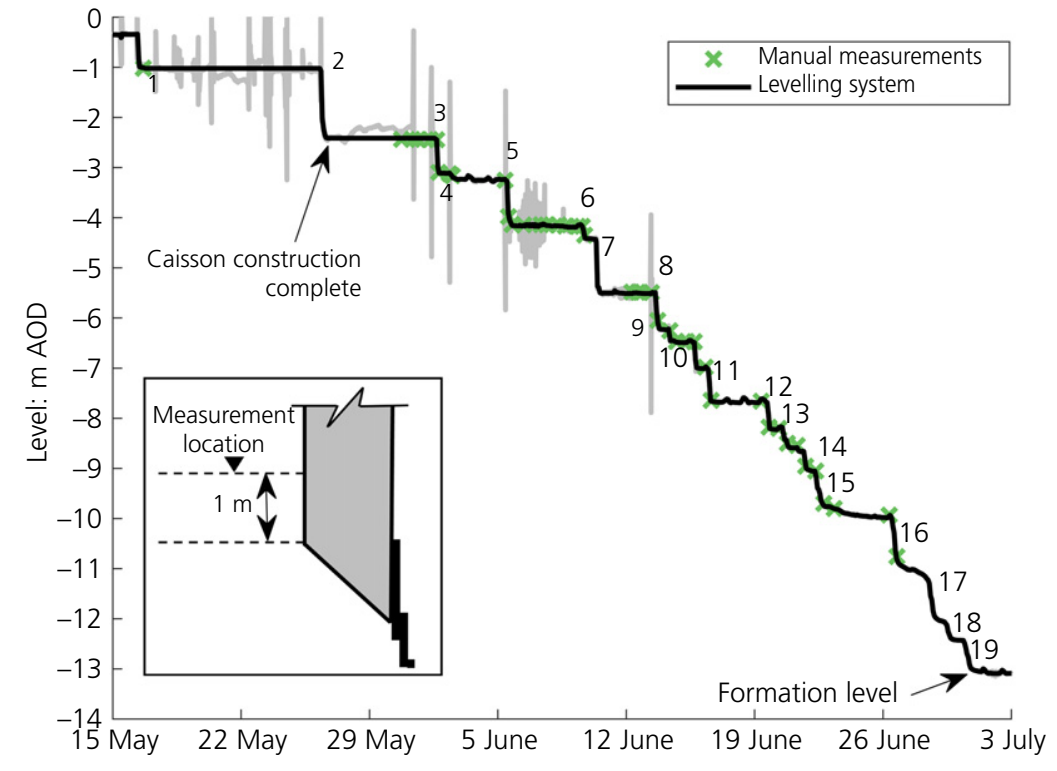

(a)

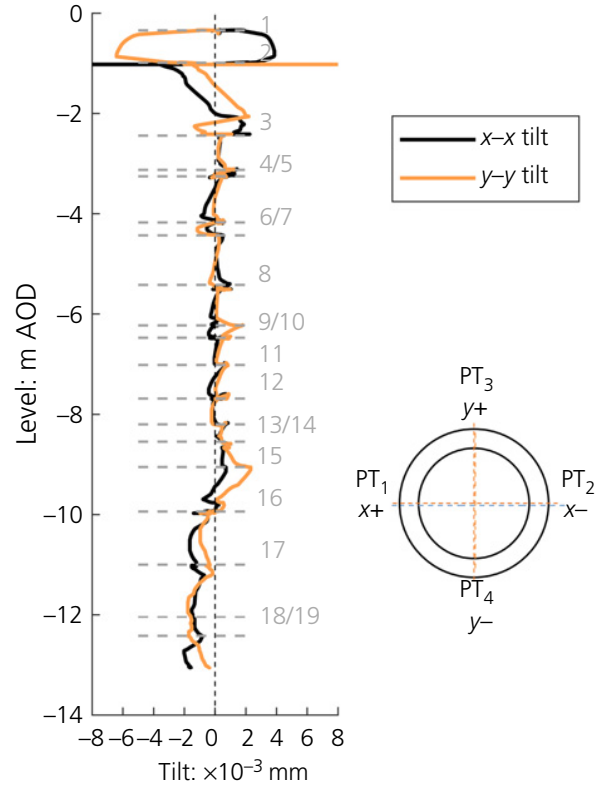

(b)

Figure 9. Caisson movements determined using the liquid-level detection system: (a) average elevation; (b) tilt. Labels 1-19 on the plot indicate movement numbers 


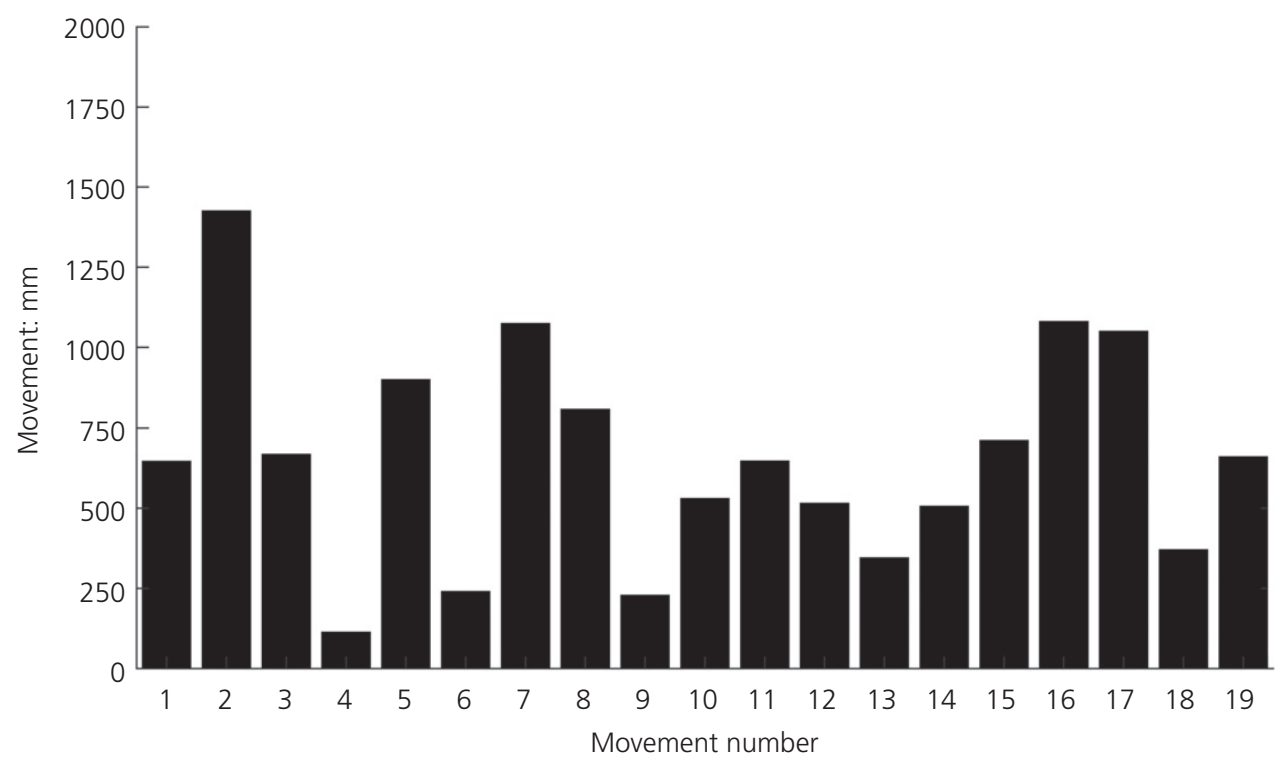

Figure 10. Summary of the magnitudes of all 19 caisson movements

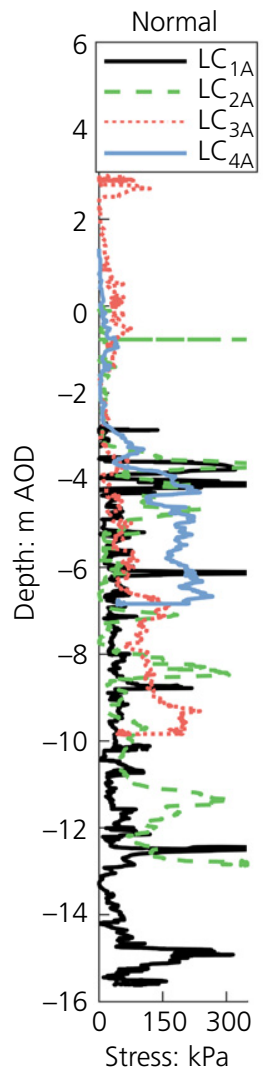

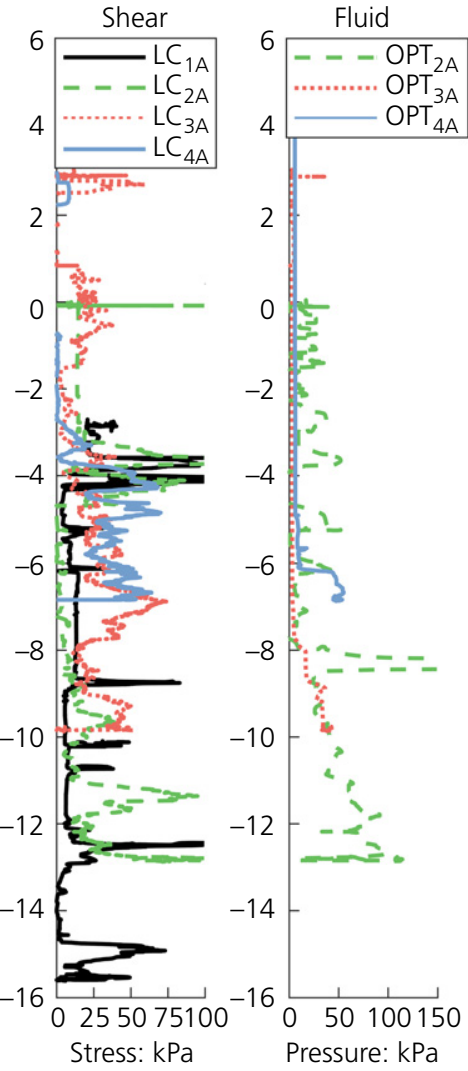

(a)
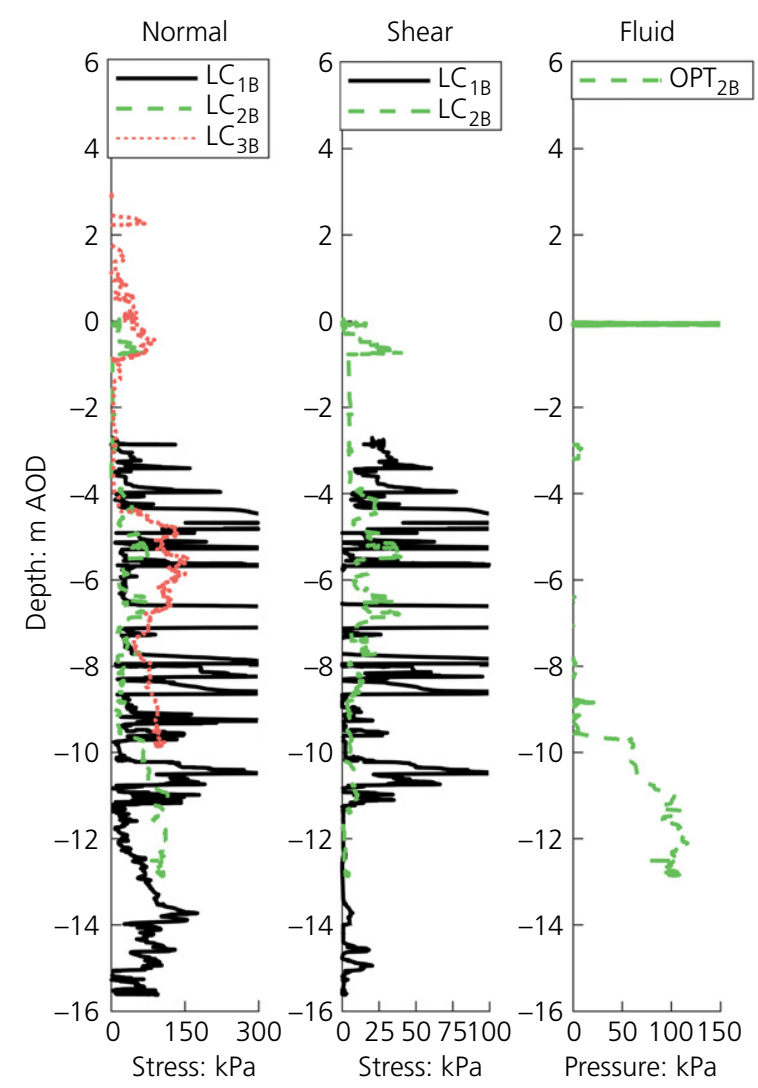

(b)

Figure 11. Soil and fluid pressures acting on the exterior face of the caisson walls determined from the three-axis LCS and PTs focused along (a) line A and (b) line B. Sensor locations are shown in Figure 5 
where $C_{\mathrm{k}}$ and $C_{\mathrm{b}}$ are the logger and strain gauge calibration factors, respectively. The strain was also compensated for temperature using

8. $\mu \varepsilon_{\text {corrected }}=\mu \varepsilon+\left(\alpha_{\mathrm{g}}-\alpha_{\mathrm{c}}\right) \Delta T$

where $\alpha_{\mathrm{g}}$ and $\alpha_{\mathrm{c}}$ are the coefficients of thermal expansion of the VW strain gauge and concrete, respectively, and $\Delta T$ is the difference in temperature from baseline readings. The coefficient of thermal expansion for the gauge was taken as $12.6 \mu \varepsilon /{ }^{\circ} \mathrm{C}$ while a value of $10 \mu \varepsilon /{ }^{\circ} \mathrm{C}$ was taken for the limestone aggregate concrete mix (Bamforth, 2007).

\section{Monitored results}

\subsection{Caisson movements}

All the data presented to the site team during construction were unfiltered. However, a Savitsky-Golay digital filter (Savitzky and Golay, 1964), with a $1 \mathrm{~h}$ time period, was applied to the level detection data retrospectively to remove peaks and noise arising from construction vibrations. Figure 9(a) shows the time history of the original measurements (grey curve) and processed measurements (black curve) of the caisson elevation during sinking. Manual measurements were also taken periodically on site using a total station to verify the accuracy of the liquid level detection system. As shown in Figure 9(a), the caisson elevation determined using the level detection system was in excellent agreement with the manual measurement. The data indicate that caisson sinking is a 'stop-start' process with, for this project, a total of 19 distinct movements identified (numbered on Figure 9(a)). The first sinking movement occurred as a result of breaking out the concrete footing beneath the caisson wall. As wall construction was complete on 27 May 2017, the total wall weight $\boldsymbol{W}$ was constant from movement 2 onwards. Subsequent movements were therefore attributable to internal excavation activities only. Measurements of the caisson tilt during sinking are presented in Figure 9(b) for two mutually orthogonal axes, $x-x$ and $y-y$. The movement numbers are again superimposed on the plot. Large tilting of the caisson was observed during the initial stages of sinking whereas only slight variations were recorded as the caisson became more embedded in the soil. This highlights the importance of establishing verticality early in the sinking process.

A summary of all 19 caisson movements is presented in Figure 10. The largest sinking movement was $1425 \mathrm{~mm}$ (movement number 2), possibly because at this point the $45^{\circ}$ cutting

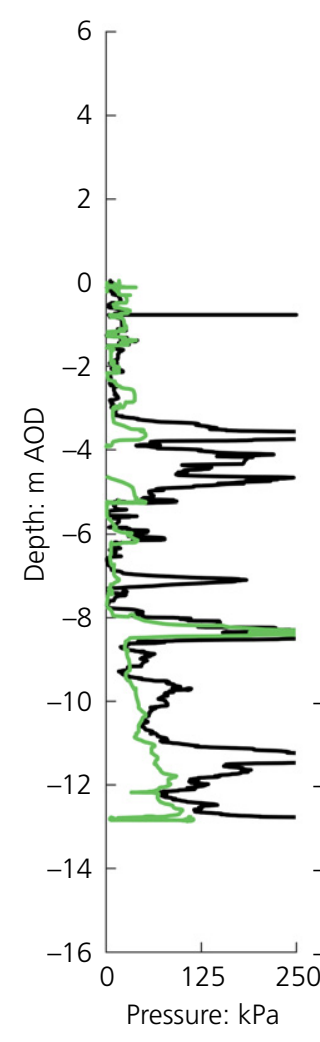

(a)

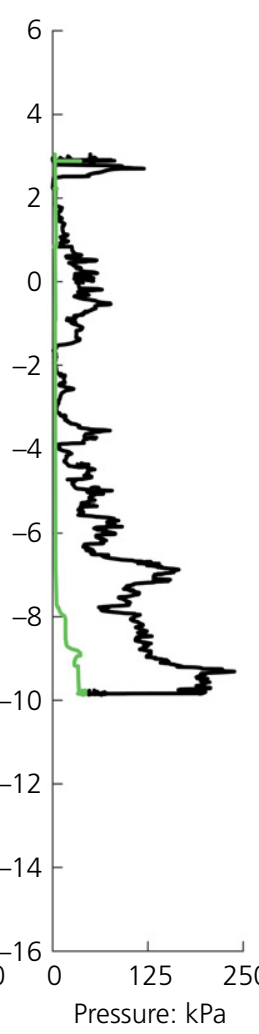

(b)

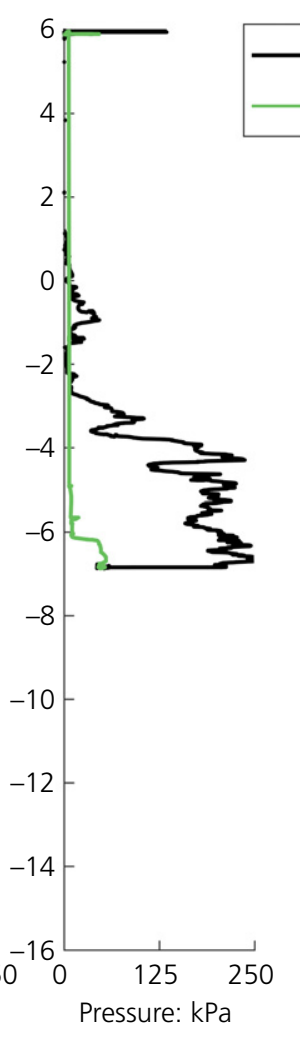

(c)

Figure 12. Comparison of total normal stress and fluid pressure measurements on the exterior face of the caisson wall along line $A$ : (a) $\mathrm{LC}_{2 \mathrm{~A}}$ and $\mathrm{OPT}_{2 \mathrm{~A}} ;$ (b) $\mathrm{LC}_{3 \mathrm{~A}}$ and $\mathrm{OPT}_{3 \mathrm{~A}} ;$ (c) $\mathrm{LC}_{4 \mathrm{~A}}$ and $\mathrm{OPT}_{4 \mathrm{~A}}$ 
face was not yet fully embedded in the soil. The average of all 19 movements was $\approx 750 \mathrm{~mm}$ or $0.6 t_{\mathrm{w}}$ ( $t_{\mathrm{w}}$ being the caisson wall thickness). Minimal differences were observed in the rate or magnitude of the caisson movements whether the cutting face was embedded in the dense sand or stiff clay. This is likely because sinking behaviour is largely determined by the soil excavation technique adopted by the (same) operatives on site.

\subsection{Soil-structure contact stresses}

The monitored variations of total normal stress, shear stress and fluid pressures with depth are plotted in Figures 11(a) and 11(b) for line A and line B respectively. Considering first the line A measurements, the total normal stresses and shear stresses monitored by $\mathrm{LC}_{1 \mathrm{~A}}$ were lower than expected throughout construction with the exception of a peak at $-15 \mathrm{~m}$ AOD.
This LC was installed radially inwards by $20 \mathrm{~mm}$ from the exterior surface of the leading edge and very close to a lubrication port. The resultant gap likely reduced the contact stresses exerted by the soil on the sensor. Measurements from the upper LCs cast flush with the caisson wall $\left(\mathrm{LC}_{2 \mathrm{~A}}-\mathrm{LC}_{4 \mathrm{~A}}\right)$ provide insight into the effectiveness of the lubricated annulus system. There were considerable fluctuations in the measurements, indicating a complex contact stress history during the sinking process. There also appears to be a consistent increase in both the total normal stress and shear stress measured by each LC as they passed a given elevation. By way of example, the shear stresses measured by $\mathrm{LC}_{4 \mathrm{~A}}$ were as high as $70 \mathrm{kPa}$ at $-5 \mathrm{~m}$ AOD, significantly greater than measurements obtained from monitoring points located lower on the wall passing the same point. This behaviour was unexpected as it goes against well-documented 'friction fatigue' behaviour observed for

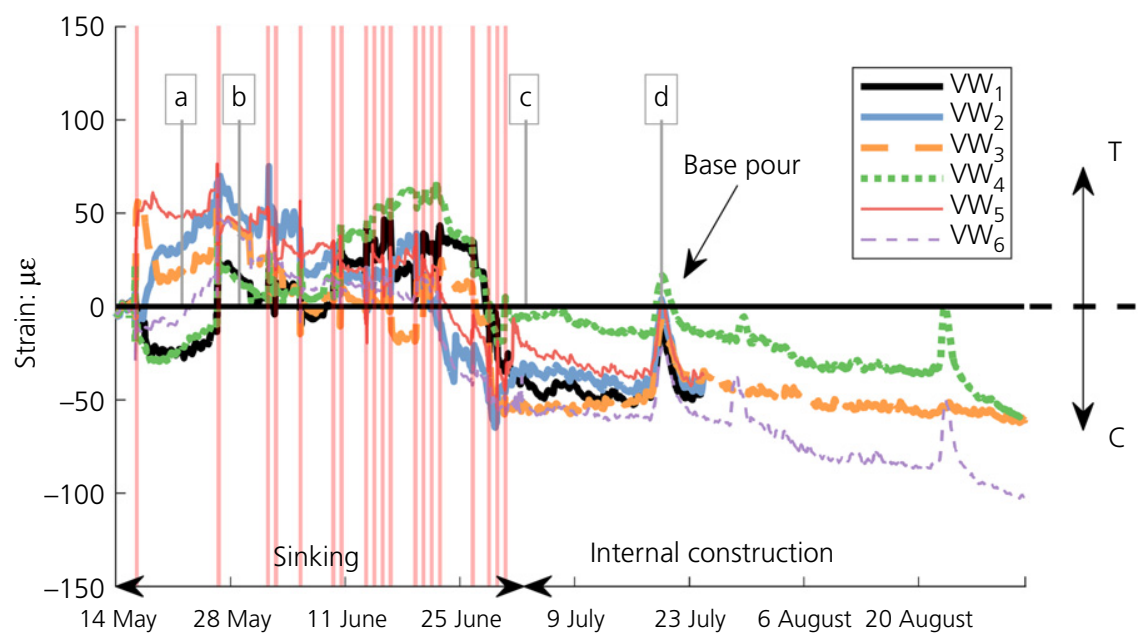

(a)

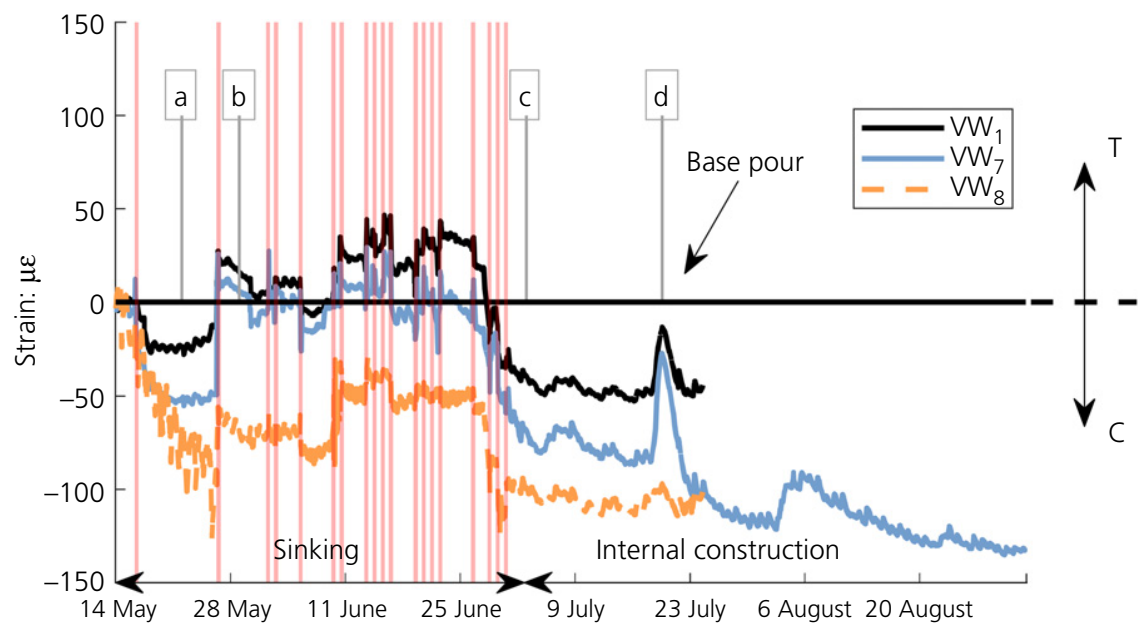

(b)

Figure 13. Time history of wall hoop strains determined from VW strain gauges distributed (a) circumferentially (constant elevation) and (b) vertically (constant circumferential location) on the caisson. The vertical grey lines denote caisson movements 
axially loaded piles (Lehane et al., 1993). The apparent failure of the lubricated annulus system can perhaps be explained by the external fluid pressure measurements $\left(\mathrm{OPT}_{2 \mathrm{~A}}-\mathrm{OPT}_{4 \mathrm{~A}}\right)$, which were almost non-existent in the sand layer (see Figure 11(a)). Dewatering of the internal excavation was achieved using a series of wellpoints located around the circumference of the cofferdam. The negative pore pressures and relatively high permeability of the sand promoted infiltration of the lubricant into the surrounding soil. The large shear stresses measured in the sand layer are therefore attributable to a collapse of the annulus. The sinking process caused sand at the caisson interface to be drawn downwards, increasing the normal effective stresses and therefore also the shear stress. By contrast, there was a linear development of fluid pressure as sensors $\mathrm{OPT}_{3 \mathrm{~A}}$ and $\mathrm{OPT}_{4 \mathrm{~A}}$ penetrated through the lower clay layer. This is to be expected given $(a)$ the much lower permeability of the clay layer (fluid losses are negligible) and (b) the fact that the fluid pressure head was attributable only to the elevation head and therefore proportional to the height of fluid in the annulus. Similar conclusions can be deduced from an analysis of the measurements presented in Figure 11(b), indicating consistent behaviour circumferentially around the caisson. Shear measurements for $\mathrm{LC}_{3 \mathrm{~B}}$ were not recorded due to cable damage during construction. It can also be seen that there were significant, albeit transient, peaks in the normal stresses and shear stresses recorded by $\mathrm{LC}_{1 \mathrm{~B}}$ due to caisson tilting.

Figure 12 shows the variation of total normal stress with depth measured by all LCs on line A. Fluid pressure measurements determined using the adjacent PTs are also plotted for comparison. Clearly the difference between these two sets of measurements corresponds to effective normal stress arising from soil contact. Figure 12(a) indicates that the annulus was stable (temporarily) during the initial stages of sinking, with good agreement found between the two sets of measurements. Below $-3 \mathrm{~m}$ AOD, significant effective normal soil stresses developed on the caisson wall in the sand layer. Comparison of Figures 12(a)-12(c) shows a progressive increase in the effective stresses determined using sensors located higher on the caisson wall. This highlights the risks associated with sinking deep caissons in cohesionless soils. In contrast, there was improved agreement between the total normal stress and support fluid pressures in the clay layer, indicating a stable annulus (see Figure 12(a)).

\subsection{Caisson wall strains during sinking}

Figure 13 shows the time history of hoop strains within the caisson wall during sinking, as determined from the VW strain gauges. Caisson movements are indicated in the plot using grey vertical lines. Figure 13(a) compares hoop strain measurements corresponding to the same elevation but distributed circumferentially around the caisson. The measurements presented in this plot are reasonably consistent and show considerable fluctuations with depth (during sinking). Surprisingly, it can be seen that the wall hoop strains were primarily tensile (T) for the majority of the sinking process where all six measurements were in good agreement. This is due to the large horizontal soil reaction that develops on the angled cutting face acting radially outwards. Comparing measurements at the same circumferential location but now distributed vertically (Figure 13(b)), it can be seen that the hoop strains were highly dependent on the vertical position of the sensor in the caisson wall. The hoop strain data in Figure 13 are replotted in Figure 14 as a function of depth. As the caisson approached formation level, the horizontal soil reaction at the base became overwhelmed by the external soil and groundwater pressures and the wall gradually experienced compressive (C) hoop strains.

To explore caisson deformation during sinking further, a qualitative comparison of the deformed shape is presented in Figures 15(a)-15(d), which respectively correspond to points marked a-d in Figure 13. Figure 15 shows that the caisson

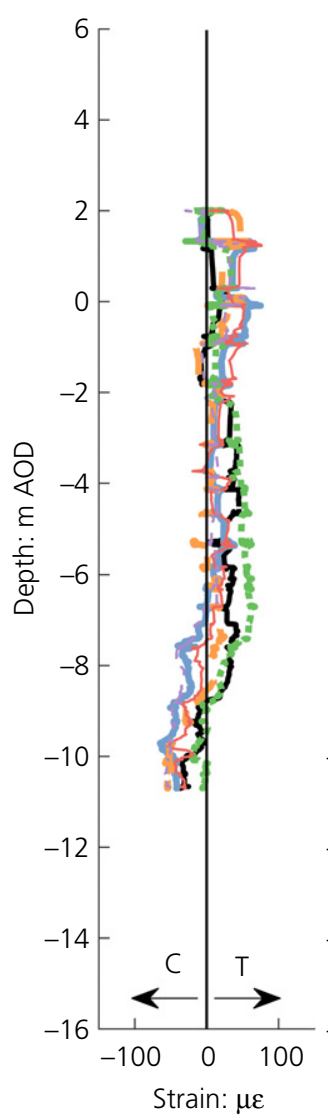

(a)

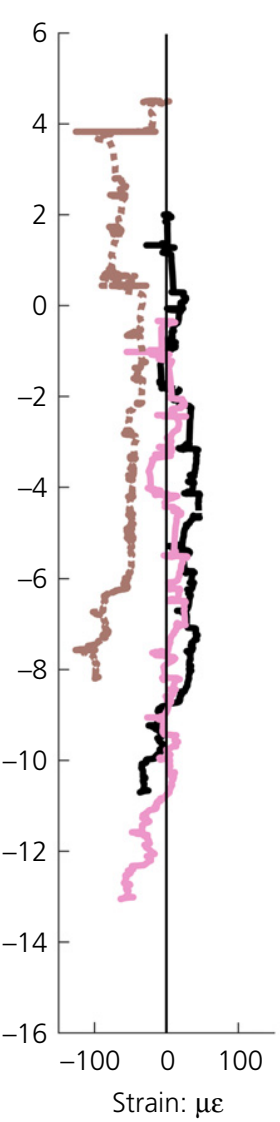

(b)
Figure 14. Variation of wall hoop strains with depth determined from VW strain gauges distributed (a) circumferentially (constant elevation) and (b) vertically (constant circumferential location) on the caisson 
experienced bending about its circumference, and therefore did not behave as a rigid body, during sinking. This ovalisation may be due to caisson tilting and the inhomogeneous soil profile applying a variable circumferential load. Figures 15(b) and $15(\mathrm{c})$ confirm the earlier observations that the initial tensile strains during sinking transitioned to compressive strains towards the end of sinking. Remarkably, the final deformed shape at the end of construction was insignificant due to the additional horizontal reaction that developed after casting of the $1.5 \mathrm{~m}$ thick concrete base.

\section{Analysis and implications for design}

\subsection{Performance of the slurry-filled annulus}

Figure 16 considers four separate events of the dissipation of the support fluid during construction recorded by $\mathrm{OPT}_{2 \mathrm{~A}}$. The peaks in fluid pressure were due to support fluid pumping during sinking periods (shown shaded in pink). There was an immediate decay in the fluid pressure following pumping in all cases, with average dissipation rates of $2.4-6.2 \mathrm{kPa} /$ day. There are two possible mechanisms for the observed dissipation in fluid pressure acting on the exterior of the caisson walls: $(a)$ infiltration of the support fluid into the surrounding soil (i.e. ineffective filter cake formation) and (b) consolidation of the support fluid. Given the high rate of pressure dissipation, the results suggest that a filter cake was not formed in the sand layer. Standard practice on site is to pump lubrication during sinking to fill the newly formed annulus volume with lubricant; the monitored data indicate that more regular pumping of lubricant into the annulus was required to account for these dissipation rates. However, the authors acknowledge that these findings may be specific to this case history and additional laboratory and field investigations are warranted before more general conclusions are drawn.

A secondary aim of the construction support fluid in this project was to minimise the caisson-soil interface friction angle $(\delta)$, which was determined from the monitored data using

9. $\delta=\tan ^{-1}\left(\frac{\tau}{\sigma_{\mathrm{n}}-p}\right)$

where $\sigma_{\mathrm{n}}$ and $\tau$ are, respectively, the total normal stresses and shear stresses measured by individual LCs and $p$ is the fluid pressure measured by the corresponding PTs.

The variation of the back-calculated values of $\delta$ with depth is shown in Figure 17; $\tan \delta=0.55$ for an unlubricated aluminium-sand interface (Potyondy, 1961) is also plotted for comparison. The manipulation of three separate signals according to Equation 9 amplified the noise in the measurements.

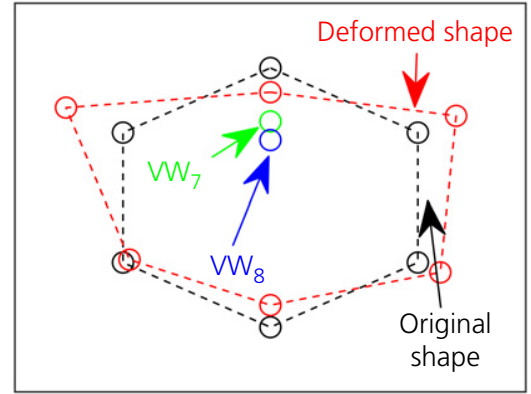

(a)

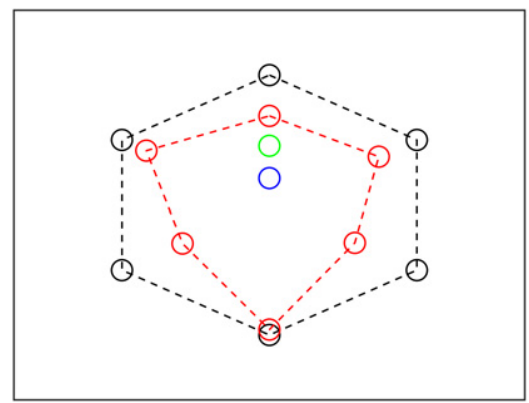

(c)

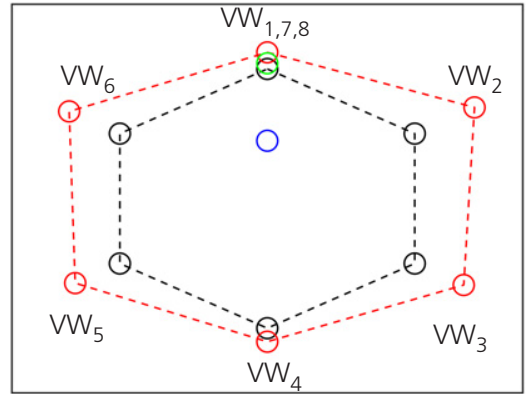

(b)

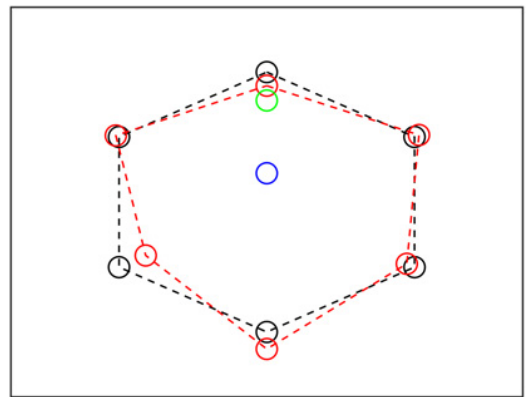

(d)

Figure 15. Original shape and magnified deformed shape of caisson from VW gauges at various dates and excavation levels. Parts (a)-(d) correspond to points a-d in Figure 13, respectively 


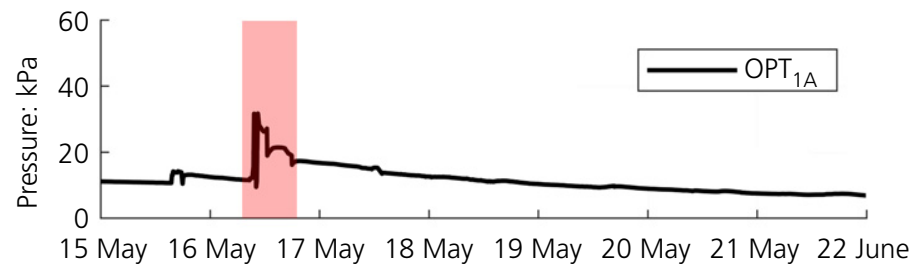

Average

dissipation $=$

$2.4 \mathrm{kPa} / \mathrm{day}$

(a)

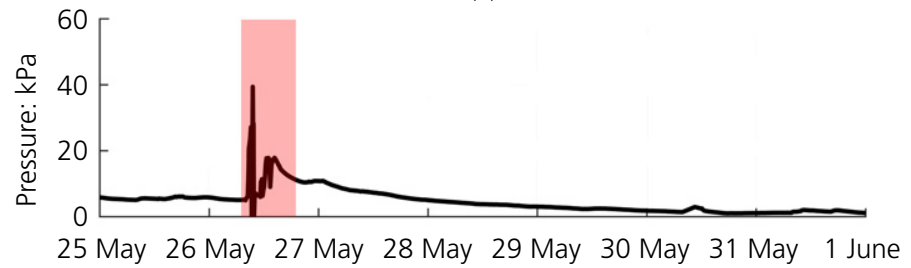

Average

dissipation $=$

$5.8 \mathrm{kPa} /$ day

(b)

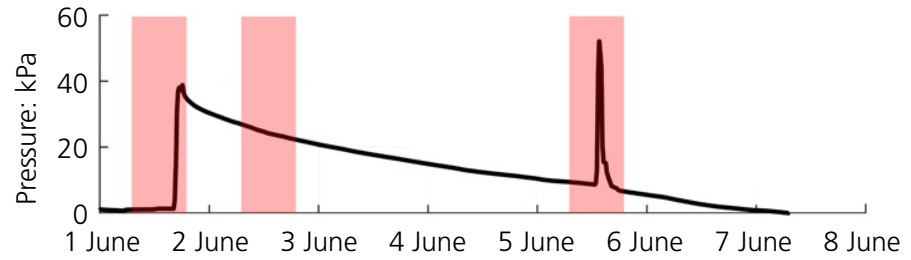

Average

dissipation $=$

$5.86 \mathrm{kPa} / \mathrm{day}$

(c)

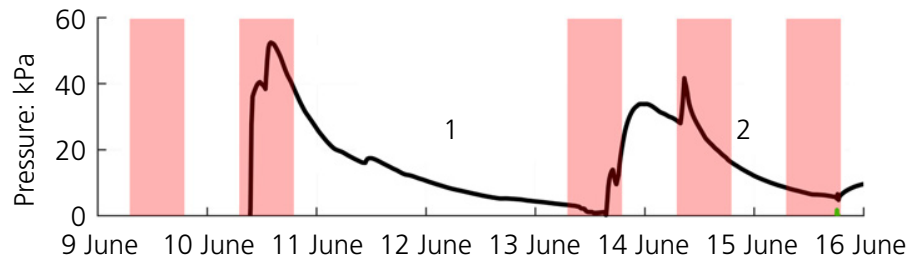

Average

dissipation $1=$

$6.2 \mathrm{kPa} / \mathrm{day}$

Average

dissipation $2=$

(d)

Figure 16. Dissipation of fluid pressure in annulus recorded by OPT $2 \mathrm{~A}$ towards the base of the caisson wall (see Figure 5) for four different events. Sinking periods are shown shaded

A $4 \mathrm{~h}$ median filter was applied to the interface friction data in Figure 17 as it provided a good compromise between smoothness and fidelity. The fluctuations in $\tan \delta$ at $-2.5 \mathrm{~m}$ AOD are a result of the caisson passing the lower guide collar, possibly developing some intermittent contact. It can also be seen that $\tan \delta$ intermittently dropped to zero at locations where the annulus was fully supported by the lubricant so that the shear stresses were zero. Aside from intermittent peaks in the data, $\tan \delta=0.55$ appears to provide a good upper bound. The lubrication therefore appears to have had a minimal effect on $\delta$ with the exception of the values reported at location 4A. It is not clear whether this is an anomaly or whether the lubricant became more effective at minimising $\delta$ over time.

\subsection{Comparison with lateral earth pressure calculations}

The variation of the measured shear stress with depth is presented in Figure 18. Equation 10 is adopted for the prediction of shear stress, assuming drained conditions prevail

10. $\tau=\gamma^{\prime} z K \tan \delta$ where $\gamma^{\prime}$ is the effective soil unit weight (taken as $20 \mathrm{kN} / \mathrm{m}^{3}$ ), $z$ is the depth below ground level and $K$ is the coefficient of lateral earth pressure. Clearly $\tau=0$ is an appropriate lower bound for an effective annulus lubrication system. An upper bound prediction is also plotted in Figure 18, taking $K=2$ and $\delta=0.55 \phi^{\prime}$ for an unlubricated interface (Potyondy, 1961) and $\phi^{\prime}=40^{\circ}$ (Figure 4). It can be seen that there exists reasonable agreement with the data. Although a value of $K=2$ provides a reasonable upper bound to the monitored data for depths greater than approximately $-4.5 \mathrm{~m} \mathrm{AOD}$, the shear stresses at shallower depths were significantly under-predicted. This highlights the difficulty of capturing soil-structure contact stresses that occur during caisson sinking within a prescriptive design approach. It is also worth remarking that this value of $K$ is significantly greater than that expected from active conditions according to Rankine theory $(K=0.22$ for $\left.\phi^{\prime}=40^{\circ}\right)$.

The data presented in Figure 18 are replotted in Figure 19 except now considered as a function of measurement location 

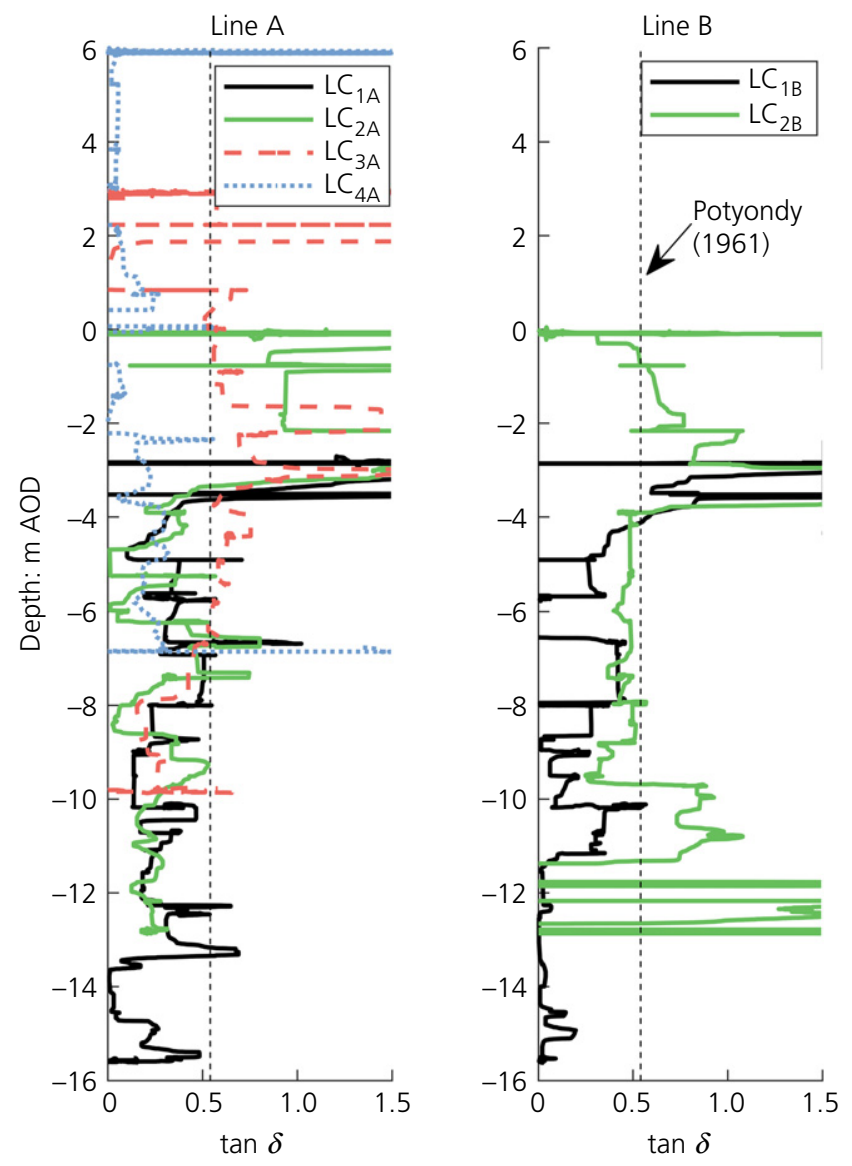

Figure 17. Variation of interface friction angle with depth deduced from LC and PT measurements on line A and line B

on the shaft wall. In light of the monitored data, it appears that while no systematic variation occurs in the interface friction angle (see Figure 17), variations in the coefficient of lateral earth pressure during sinking should be considered in design.

\section{Conclusions}

A field monitoring case history of the sinking performance of a large-diameter caisson at a UK sand site has been described. To inform the construction process, a monitoring system was developed to provide real-time information to the site team. The monitoring system allowed the measurement of $(a)$ settlement and tilt of the caisson during sinking, $(b)$ soil-structure interaction contact stresses, $(c)$ lubricant pressures and $(d)$ caisson wall strains. The main conclusions from this study are as follows.

(a) Caisson sinking, as determined using the new level detection system, is a stop-start process, with 19 distinct drops in elevation identified in this study. Large tilting of the caisson was observed in the initial stages of sinking, which reduced as the caisson became further embedded in the soil. The difficulty in re-correcting tilt once a caisson is embedded in soil underlines the importance of establishing verticality of the caisson early in the sinking phase.

(b) The monitored data revealed a complex soil-structure interaction history during sinking. In particular, normal stresses and shear stresses applied by the soil to a $100 \mathrm{~mm}$ square area on the exterior surface of the caisson were observed to increase during the sinking process. This behaviour was unexpected as it contradicts well-documented friction fatigue behaviour observed for axially loaded piles. It is likely this behaviour would persist if the caisson was sunk to a greater depth, highlighting the risk of sinking deep caissons in cohesionless materials.

(c) The recorded hoop strains showed considerable fluctuations during sinking. Surprisingly, tensile hoop strains were observed for the majority of the sinking process due to the large horizontal soil reaction that developed on the angled cutting face acting radially outwards. As the caisson approached formation level, the horizontal soil reaction at the base became overwhelmed by the external soil and groundwater pressures and the wall gradually experienced compressive hoop strains. The development of hoop strain was also highly dependent on the vertical position of the sensor where tensile strains are more likely to be developed towards the base of the wall. It was also notable that the caisson did not behave as a rigid body during sinking, with bending around the caisson circumference observed.

(d) The specific lubricated annulus system adopted for this project was largely ineffective in the sand layer. High dissipation rates of $2.4-6.2 \mathrm{kPa}$ /day meant the annulus was unsupported for prolonged periods, allowing it to collapse on the exterior surface of the caisson. In contrast, a stable annulus appeared to be achieved in the deeper clay layer. The monitored data also revealed that the interface friction angle was largely unaffected by the lubricant. Only measurements from the highest monitoring point on the wall indicted a reduction in the interface friction angle.

(e) Comparisons with predictions determined using a simplified prescriptive design method revealed the difficulty of capturing the soil-structure contact stresses that develop during caisson sinking. In particular, future predictive approaches should consider the variation of the coefficient of lateral earth pressure during sinking. Further experimental and field investigations of these effects are warranted for the development of a more robust design methodology.

\section{Acknowledgements}

The authors gratefully acknowledge the financial and in-kind support of Ward and Burke Construction Ltd for this research, 


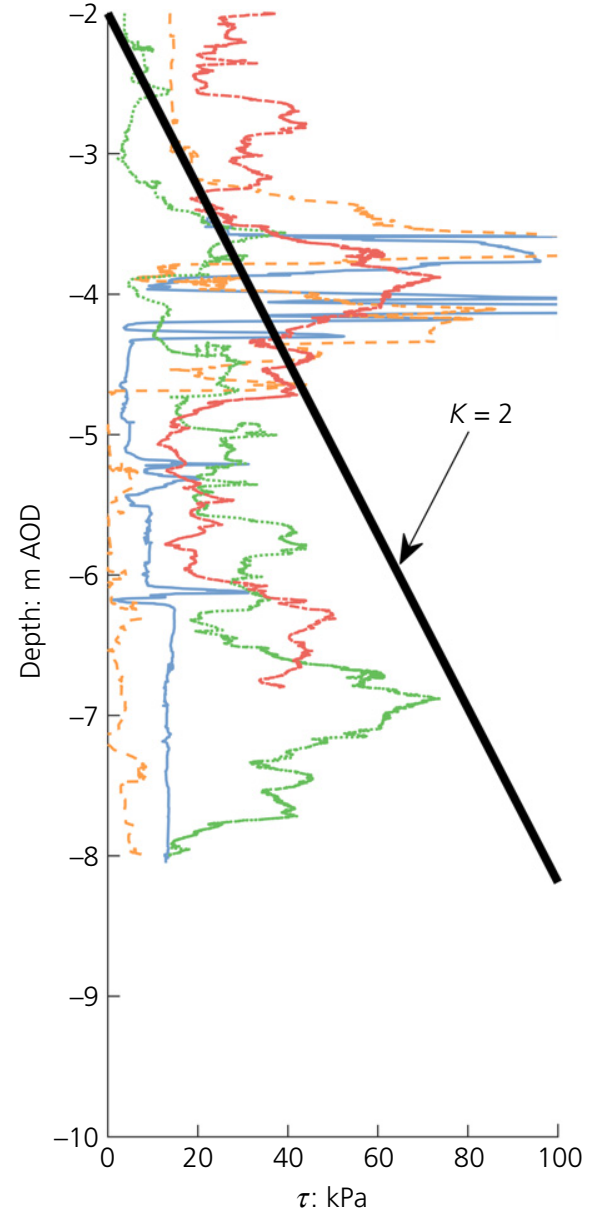

(a)
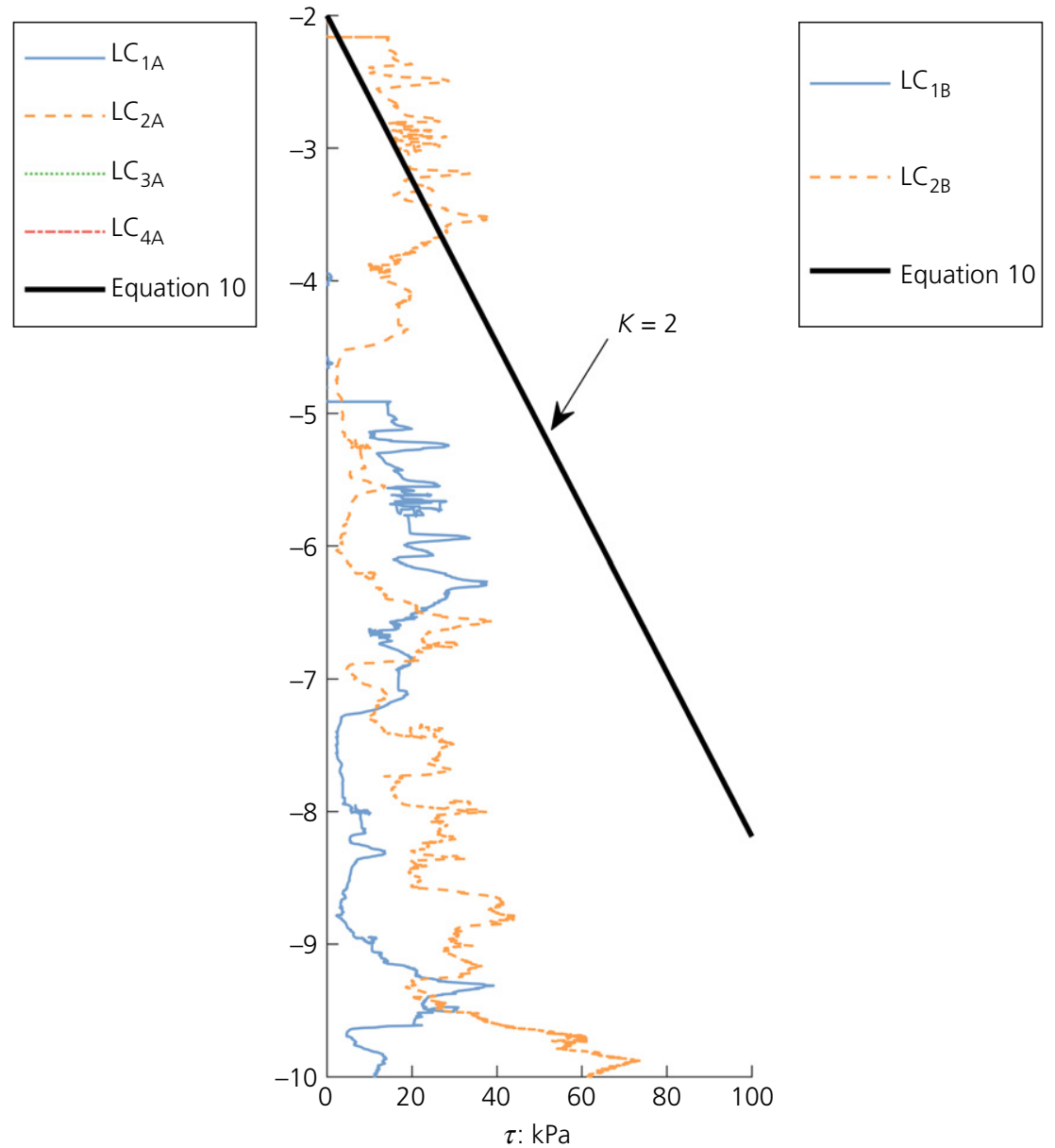

(b)

Figure 18. Comparison of monitored data and simplified predictions of the variation of soil-structure shear stresses with depth: (a) line $A ;(b)$ line $B$

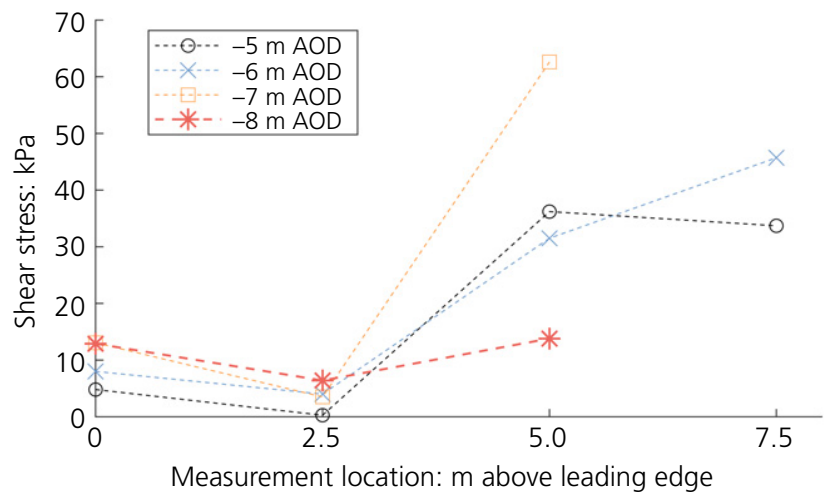

Figure 19. Comparison of monitored data and simplified predictions of the variation of the coefficient of lateral earth pressure with measurement location on the caisson wall

as well as the efforts of the site team at Anchorsholme Park. Sheil is supported by the Royal Academy of Engineering under the Research Fellowship scheme. Byrne is supported by the Royal Academy of Engineering under the Research Chairs and Senior Research Fellowships scheme.

\section{REFERENCES}

Abdrabbo F and Gaaver K (2012) Challenges and uncertainties relating to open caissons. DFI Journal 6(1): 21-32.

Allenby D, Waley G and Kilburn D (2009) Examples of open caisson sinking in Scotland. Proceedings of the Institution of Civil Engineers - Geotechnical Engineering 162(1): 59-70, https://doi. org/10.1680/geng.2009.162.1.59.

Bamforth PB (2007) Early-age Thermal Crack Control in Concrete. Ciria, London, UK.

Chandler J, Hinch L, Fair R et al. (1984) Jamuna River 230 kV crossing, Bangladesh. Part 2: construction. IEE Proceedings $C$ - Generation, Transmission and Distribution 131(7): 319-332.

Fischer GR, Gerszewski WL, Barchok FJ and Yavarow MK (2004) Deep caisson sinking in soft soils, Grand Forks, North Dakota.

Proceedings of the 5th International Conference on Case Histories in Geotechnical Engineering, New York, NY, USA. University of Missouri, Rolla, MO, USA. Paper No. 1.67.

Ho CE (2002) Settlement performance of large diameter friction caissons in bouldery clay. In Deep Foundations 2002: An 
International Perspective on Theory, Design, Construction, and Performance (O'Neill MW and Townsend FC (eds)). ASCE, Reston, VA, USA, pp. 525-541.

Jamiolkowski M, Lo Presti D and Manassero M (2003) Evaluation of relative density and shear strength of sands from cpt and dmt. In Soil behavior and soft ground construction, pp. 201-238.

Kulhawy FH and Mayne PW (1990) Manual on Estimating Soil Properties for Foundation Design. Electric Power Research Institute, Palo Alto, CA, USA.

Lehane BM, Jardine RJ, Bond AJ and Frank R (1993) Mechanisms of shaft friction in sand from instrumented pile tests. ASCE Journal of Geotechnical Engineering 119(1): 19-35.

New B and Bowers K (1994) Ground movement model validation at the Heathrow Express trial tunnel. In Tunnelling ' 94 (Arthur LJ (ed.)). Springer, Boston, MA, USA, pp. 301-329.

Newman T and Wong HY (2011) Sinking a jacked caisson within the London basin geological sequence for the Thames water ring main extension. Quarterly Journal of Engineering Geology and Hydrogeology 44(2): 221-232.

Nonveiller E (1987) Open caissons for deep foundations. ASCE Journal of Geotechnical Engineering 113(5): 424-439.

Potyondy JG (1961) Skin friction between various soils and construction materials. Géotechnique 11(4): 339-353, https://doi.org/10.1680/geot.1961.11.4.339.

Royston R, Phillips BM, Sheil BB and Byrne BW (2016) Bearing capacity beneath tapered blades of open dug caissons in sand. Proceedings of Civil Engineering Research in Ireland 2016 Conference, Galway,
Ireland (Jamie G (ed.)). Civil Engineering Research Association of Ireland, pp. 473-478.

Safiullah A (2005) Geotechnical problems of bridge construction in Bangladesh. In Proceedings of the Japan-Bangladesh Joint Seminar on Advances in Bridge Engineering, vol. 10, pp. 135-146.

Savitzky A and Golay MJ (1964) Smoothing and differentiation of data by simplified least squares procedures. Analytical Chemistry 36(8): 1627-1639.

Schwamb T (2014) Performance Monitoring and Numerical Modelling of a Deep Circular Excavation. PhD thesis, University of Cambridge, Cambridge, UK.

Schwamb T, Soga K, Mair RJ et al. (2014) Fibre optic monitoring of a deep circular excavation. Proceedings of the Institution of Civil Engineers - Geotechnical Engineering 167(2): 144-154, https://doi.org/10.1680/geng.13.00036.

Schwamb T, Elshafie MZ, Soga K and Mair RJ (2016) Considerations for monitoring of deep circular excavations. Proceedings of the Institution of Civil Engineers - Geotechnical Engineering 169(6): 477-493, https://doi.org/10.1680/jgeen.15.00063.

Stubbs FW (1996) Standard Handbook of Heavy Construction, 3rd revised edn. McGraw-Hill, New York, NY, USA.

Tomlinson MJ (2001) Foundation Design and Construction, 7th edn. Prentice Hall, Harlow, UK.

Yao Q, Yang XG and Li HT (2014) Construction technology of open caisson for oversize surge shaft in drift gravel stratum. Electronic Journal of Geotechnical Engineering 19: 5725-5738. 